\begin{tabular}{|c|c|}
\hline Title & Relaxation Dynamics and Underlying Mechanism of a Thermally Reversible Gel from Symmetric Triblock Copolymer \\
\hline Author(s) & $\begin{array}{l}\text { Ye, Y a Nan; Cui, Kunpeng; Indei, T sutomu; Nakajima, T asuku; Hourdet, Dominique; Kurokawa, Takayuki; Gong, Jian } \\
\text { Ping }\end{array}$ \\
\hline Citation & $\begin{array}{l}\text { Macromolecules, 52(22), 8651-8661 } \\
\text { https://doi .org/10.1021/acs.macromol.9b01856 }\end{array}$ \\
\hline Issue Date & 2019-11-26 \\
\hline Doc URL & http:/hdl.handle.net/2115/79694 \\
\hline Rights & $\begin{array}{l}\text { This document is the A ccepted Manuscript version of a Published Work that appeared in final form in Macromolecules, } \\
\text { copyright @ A merican Chemical Society after peer review and technical editing by the publisher. To access the final } \\
\text { edited and published work see https:/pubs.acs.org/doi/10.1021/acs.macromol.9b01856. }\end{array}$ \\
\hline Type & article (author version) \\
\hline File Information & Macromolecules 20191105.pdf \\
\hline
\end{tabular}

Instructions for use 


\title{
Relaxation Dynamics and Underlying Mechanism of a Thermally Reversible Gel from Symmetric Triblock Copolymer
}

Ya Nan Ye ${ }^{1}$, Kunpeng Cui ${ }^{2 *}$, Tsutomu Indei ${ }^{3}$, Tasuku Nakajima ${ }^{1,2,3}$, Dominique Hourdet ${ }^{3,4}$, Takayuki Kurokawa ${ }^{1,3}$ and Jian Ping Gong ${ }^{1,2,3^{*}}$

${ }^{1}$ Faculty of Advanced Life Science, Hokkaido University, Sapporo 001-0021, Japan, ${ }^{2}$ Institute for Chemical Reaction Design and Discovery (WPI-ICReDD), Hokkaido University, Sapporo 001-0021, Japan,

${ }^{3}$ Global Institution for Collaborative Research and Education (GI-CoRE), Hokkaido University, Sapporo 001-0021, Japan.

${ }^{4}$ Laboratoire Sciences et Ingénierie de la Matière Molle, ESPCI Paris, PSL University, Sorbonne Université, CNRS, Paris, F-75005, France.

*: Corresponding author, Email: kpcui@sci.hokudai.ac.jp, gong@sci.hokudai.ac.jp

\begin{abstract}
We report a novel thermally responsive system from poly(butyl methacrylate)- $b$-poly(methacrylic acid)-b-poly(butyl methacrylate)
\end{abstract} (PBMA- $b$-PMAA- $b$-PBMA) triblock copolymer in dimethylformamide (DMF) solvent. This system shows a sol-gel transition by cooling below a critical temperature $T_{\mathrm{c}}$. The network relaxation time of these gels rightly fall in the typical rheological experiment window, permitting us to investigate the relaxation dynamics and underlying mechanism, with a combination of linear rheology, time-resolved small-angle X-ray scattering (SAXS), and temperature-elevated nuclear magnetic resonance (NMR) measurements. Both time-temperature superposition (TTS) and time-concentration superposition (TCS) are well hold in this system. The relaxation dynamics at temperatures below and above $T_{\mathrm{c}}$ are quite different, giving two different activation energy $E_{1 \mathrm{a}}$ and $E_{2 \mathrm{a}}$, respectively. The 
$E_{1 \text { a }}$, being polymer concentration independent, is related to micelle formation of end blocks, while the concentration dependent $E_{2 \mathrm{a}}$ is related to the chain friction of entangled polymer solution. By coupling linear rheology, SAXS, and NMR, we quantitatively estimated the fraction of bridge, loop, and dangling chains. The longest relaxation time of the gel, $\tau_{\mathrm{L}}$, strongly depends on polymer concentration, attributing to the increased connectivity of micellar network. By combining the shift factors $a_{\mathrm{T}}$ and $a_{\mathrm{C}}$ determined from TTS and TCS, respectively, we can obtain the $\tau_{\mathrm{L}}$ at any given temperature and concentration from that at reference temperature and concentration. 


\section{Introduction}

In the past decades, physically associating gels from ABA triblock copolymers have attracted considerable attention due to their application importance. When ABA copolymers dissolve in a B block selective solvent at sufficiently high concentration, they self-assemble into a percolating network, with A blocks aggregating into micelles bridged by $\mathrm{B}$ blocks ${ }^{1,2}$. Benefiting from both the liquid and solid nature, these gels have a wide variety of applications, spanning from 3D printing ${ }^{3}$, flexible electrode ${ }^{4,5}$, drug release $^{6}$, tissue engineering ${ }^{7}$, to tough and self-healing structural biomaterials ${ }^{8,9}$. Theoretical ${ }^{10,11}$ and experimental efforts ${ }^{12,13}$ have been made to understand the self-assembly behavior and relaxation dynamics of the ABA triblock copolymers systems under a wide variety of conditions.

Depending on the strength of end block-solvent interaction, the self-assembly of ABA copolymers can be divided into two groups. One is that the micelles are dynamic (or kinetically active) and the end blocks in different micelles can exchange spontaneously. In this case, the gel has a transient network and shows strong viscoelastic response ${ }^{14,15}$. Another is that the micelles are in glassy state and the end blocks exchange between micelles is kinetically frozen. In this case, the gel displays almost pure elasticity, like a chemical gel with covalent crosslinking ${ }^{16-18}$. The strength of end block-solvent interaction can be changed by many stimuli, such as $\mathrm{pH}^{13}$, solvent quality ${ }^{14}$, temperature ${ }^{15,19}$, and so on. Among them, the self-assembly induced by temperature change (or thermally induced self-assembly) is not well understood compared to others. One major reason is that the micelle in such systems is usually in glassy state and the relaxation time is immeasurably long $^{13,20}$. Therefore, other stimuli were used instead of temperature, to mimic the situation 
that happened in thermally induced self-assembly of triblock copolymers. For example, Shull et al. ${ }^{14}$ reported that the change in solvent composition can be equivalent to the change in temperature for inducing self-assembly of polyelectrolyte-containing triblock copolymers. There are also some reports on the thermally induced assembly with relaxation time in the right observation window. Unfortunately, the rheological and structural measurements were not well combined in those studies ${ }^{1,14,21,22}$. As the self-assembly and relaxation dynamics are coupled, a combined study in rheological behavior and structural evolution is necessary for the better understanding of this subject.

In this work, we report a novel thermally induced self-assembly system and unveil the underlying mechanism. The system is from amphiphilic ABA triblock copolymers, poly(butyl methacrylate)- $b$-poly(methacrylic acid)- $b$-poly(butyl methacrylate) (PBMA- $b$-PMAA- $b$-PBMA) in dimethylformamide (DMF). By combining the linear oscillatory shear measurements, small-angle X-ray scattering (SAXS) and nuclear magnetic resonance (NMR), the self-assembly process and the relaxation dynamics at varied temperatures and polymer concentrations are clarified. Our results show that, in DMF, the PBMA end blocks self-assemble into micelles to form a transient network upon cooling, and the relaxation time of transient network varies with temperature and polymer concentration, following the time-temperature superposition (TTS) and time-concentration superposition (TCS) principles.

\section{Experiments}


2.1 Materials. The amphiphilic triblock copolymers, poly(butyl methacrylate)- $b$-poly(methacrylic acid)- $b$-poly(butyl methacrylate) (PBMA- $b$-PMAA- $b$-PBMA) and the corresponding homopolymers PBMA and PMAA were provided by the Otsuka Chemical Co., Ltd., Japan (Table 1). The solvent dimethylformamide (DMF) were purchased from Wako Pure Chemical Industries, Ltd. (Japan).

Sample solutions were prepared as follows. The polymer was dissolved in DMF solution with desired monomeric concentrations $C_{\mathrm{P}}$ ranging from 0.91 to $2.21 \mathrm{~mol} / \mathrm{L}$, which corresponds to polymer weight fractions ranging from $11.5 \mathrm{wt} \%$ to $28.0 \mathrm{wt} \%$ (Table S1). The solutions were homogenized by stirring for $12 \mathrm{~h}$ at room temperature and then were left standing at least for a night before measurements.

2.2 Rheology. An ARES-2 rheometer (TA Instruments) was used with a concentric cylinder geometry of $9.30 \mathrm{~mm}$ bob radius, $10.00 \mathrm{~mm}$ cup radius and $27.95 \mathrm{~mm}$ bob length. A schematic of this geometry is shown in Figure S1. Dynamic measurements were performed in the linear viscoelastic regime. The temperature sweep was performed from $-20{ }^{\circ} \mathrm{C}$ to $25{ }^{\circ} \mathrm{C}$ with a heating/cooling rate of $1{ }^{\circ} \mathrm{C} \mathrm{min}-1$, for a maximum strain of $0.5 \%$, and a frequency of $10 \mathrm{rad} \mathrm{s}^{-1}$. The frequency sweep was performed from 0.01 to $100 \mathrm{rad}$ $\mathrm{s}^{-1}$ with a maximum strain of $0.5 \%$ over a temperature range of $-20{ }^{\circ} \mathrm{C}$ to $35{ }^{\circ} \mathrm{C}$ with an interval of $5{ }^{\circ} \mathrm{C}$. The data was processed using the manual shifting mode to perform superpositions and spectrum calculations.

2.3 Smal-angle X-ray scattering (SAXS). The SAXS measurements were performed at BL19U2 beamline at the National Center for Protein Sciences Shanghai, China. The 
wavelength of X-ray was $1.033 \AA$ and the sample-to-detector distance was $5730 \mathrm{~mm}$. The samples were sealed in quartz capillary with a diameter of $1.5 \mathrm{~mm}$ and fixed on a Linkam thermal stage (Scientific Instruments, Waterfield, Surrey, England). The data acquisition time was $20 \mathrm{~s}$ per frame for the two-dimensional (2D) SAXS images. All scattering images were analyzed with Fit2D software from European Synchrotron Radiation Facility and corrected for the detector spatial distortion, X-ray beam fluctuation and background scattering.

2.4 Nuclear magnetic resonance (NMR). All the NMR measurements were performed on a Bruker AVANCE III HD spectrometer operating at $800 \mathrm{MHz}$ for ${ }^{1} \mathrm{H}$, using DMF-d ${ }^{7}$ as solvent. The solutions with triblock concentrations of $0.79,1.03,1.98$ and $2.21 \mathrm{~mol} / \mathrm{L}$ were selected for variable-temperature tests. The temperature control was achieved by a Bruker BCU II unit. The samples were firstly cooled to $-30{ }^{\circ} \mathrm{C}$, and then heated to $50{ }^{\circ} \mathrm{C}$ step by step with $5{ }^{\circ} \mathrm{C}$ interval to measure NMR spectra. Before each measurement, the samples were held at the set temperature for $5 \mathrm{~min}$ to reach the equilibrium.

Table 1. Triblock copolymer and homopolymers used in this work.

\begin{tabular}{cccc}
\hline & ${ }^{\mathbf{b})} \boldsymbol{M}_{\mathbf{n}}$ & ${ }^{\mathrm{c})} \boldsymbol{M}_{\mathbf{w}} \boldsymbol{M}_{\mathbf{n}}$ & $\boldsymbol{f}_{\mathbf{B}}$ \\
\hline${ }^{\mathbf{a})} \mathrm{A}_{75} \mathrm{~B}_{81} \mathrm{~A}_{75}$ & 28.6 & 1.38 & 0.35 \\
\hline $\mathrm{A}_{223}$ & 37.1 & 1.22 & 0 \\
\hline $\mathrm{B}_{498}$ & 42.9 & 1.37 & 1 \\
\hline
\end{tabular}

a) A and B represent poly(butyl methacrylate) (PBMA) and poly(methacrylic acid) (PMAA), respectively; the subscripts represent the degree of polymerization; ${ }^{\mathrm{b}, \mathrm{c})} M_{\mathrm{n}}, M_{\mathrm{w}}$ and $M_{\mathrm{w}} / M_{\mathrm{n}}$ represent the number-averaged molecular weight, weight-averaged molecular weight and the polydispersity of polymers, respectively; ${ }^{\mathrm{d})} f_{\mathrm{B}}$ represents monomeric molar fraction of PMAA blocks in a polymer.

\section{Results and discussions}


Thermally reversible sol-gel transition. First, we give a demonstration of the thermally induced self-assembly behavior of PBMA- $b$-PMAA- $b$-PBMA in DMF. Figure 1a shows the temperature sweep linear rheological behavior for a representative copolymer solution with $C_{\mathrm{P}}$ of $1.98 \mathrm{~mol} / \mathrm{L}$ at a fixed frequency $10 \mathrm{rad} / \mathrm{s}$. A profound increase in both storage modulus $\left(G^{\prime}\right)$ and loss moduli $\left(G^{\prime \prime}\right)$ is observed upon cooling from $25{ }^{\circ} \mathrm{C}$ to $-20{ }^{\circ} \mathrm{C}$. The storage modulus $G^{\prime}$ intersects with $G^{\prime \prime}$ at a temperature around $0{ }^{\circ} \mathrm{C}$. Above this temperature, $G^{\prime}<G^{\prime \prime}$ and the system shows a feature of the viscous solution behavior, as demonstrated by the optical image at $25{ }^{\circ} \mathrm{C}$ (inset in Figure 1a). Below this temperature, $G^{\prime}>G^{\prime \prime}$, the system becomes elastically dominant. Within the experimental timescale which is comparable to the network relaxation time, the system shows a gel behavior, as demonstrated by the optical image at $-20{ }^{\circ} \mathrm{C}$ (inset in Figure 1a). The temperature-dependent rheological behavior is reversible with no hysteresis between heating and cooling. This result suggests that the PBMA end blocks of the triblock copolymers self-assemble into micellar aggregates upon cooling, which act as physical crosslinkers to form a transient network, and the thermally induced sol-gel transition is in thermodynamically equilibrium state.

To confirm that PBMA is responsible for the micellar aggregates, we compared the rheological behaviors of DMF solutions of homopolymers PBMA and PMAA with the same monomer concentration as the above triblock copolymers (Figure S2). At $25{ }^{\circ} \mathrm{C}$, both samples form homogeneous solutions (sol state). Conversely the solubility behavior is remarkably different at $-20{ }^{\circ} \mathrm{C}$. Indeed, while the PMAA sample still shows a sol state, the PBMA sample shows precipitation. This confirms that the micellar aggregates were 
formed by the PBMA end blocks. At low temperature, the mixability between the end block and solvent molecules becomes poor, and the end blocks form micelles. Above the entanglement concentration, which is $0.79 \mathrm{~mol} / \mathrm{L}$ for our triblock copolymers (Figure $\mathbf{S 3}$ ), the micellization leads to formation of an interconnected network in which the micelles serve as multiple crosslinkers.

Temperature sweep rheology. First, we tried to determine the gelation point of our system by temperature sweep of rheological measurement. The Winter-Chambon criterion was usually used to determine gelation point or gelation temperature ${ }^{23}$. This criterion was firstly developed for chemical gels ${ }^{23}$ and then was extended to kinetically frozen physical gels ${ }^{24}$. According to this criterion, at the gelation point the moduli scale in an identical fashion with frequency, exhibiting a frequency independent loss factor $\tan \delta=G^{\prime} / G^{\prime \prime}$ at gelation point. With our system, the $\tan \delta$ curves at different frequencies show monotonous increase with temperature without crossover (Figure S4), suggesting the failure of Winter-Chambon criterion. The temperature at which $G^{\prime}=G^{\prime \prime}$ is also usually used as the apparent gelation temperature, $T^{\prime}{ }_{\text {gel }}{ }^{14}$. The apparent gelation temperature, $T_{\text {gel }}^{\prime}$, is frequency dependent, increasing with the imposed frequency. For our system, as shown in Figure $1 \mathrm{~b}, T^{\prime}$ gel obtained at $0.1 \mathrm{rad} / \mathrm{s}$ is around $-8{ }^{\circ} \mathrm{C}$, while it increases to about $6{ }^{\circ} \mathrm{C}$ for frequency at $50 \mathrm{rad} / \mathrm{s}$. The frequency dependency of $T_{\text {gel }}^{\prime}$ indicates the finite lifetime of the crosslink points (micelles) formed by the self-assembly of end block chains. That is, in our system, the micelles are dynamic and the lifetime of the end blocks pulling out from micelle is comparable with the experimental observation time. 

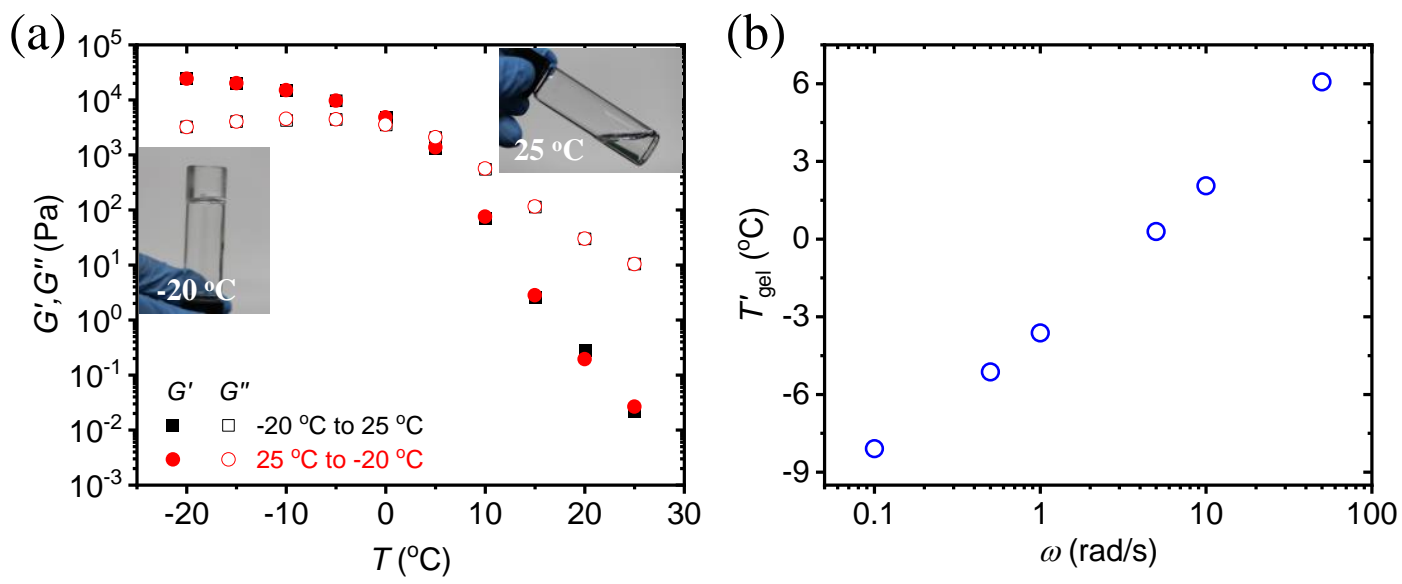

Figure 1. (a) Temperature dependence of storage modulus $G^{\prime}$ (filled) and loss modulus $G^{\prime \prime}$ (unfilled) at $\omega=10 \mathrm{rad} / \mathrm{s}$ for triblock copolymer/DMF with a concentration $C_{\mathrm{P}}$ of $1.98 \mathrm{~mol} / \mathrm{L}$. The insert photographs show the system at gel state $\left(-20^{\circ} \mathrm{C}\right)$ and sol state $\left(25^{\circ} \mathrm{C}\right)$. The heating and cooling data are completely overlapping. (b) Frequency dependence of the gelation temperature, $T_{\text {gel, }}^{\prime}$, at which $G^{\prime}=$ $G^{\prime \prime}$.

Frequency sweep rheology. According to previous studies, the relaxation of physically associating triblock copolymer gels possesses two important time scales ${ }^{12,26}$ : a short time scale controlled by the life time of end block in the micelles and a long time scale representing the relaxation of whole gel network. The latter, which is the longest relaxation time of the gel, $\tau_{\mathrm{L}}$, can be obtained from the frequency dependence of dynamic moduli. Figure 2a depicts the frequency $(\omega)$ sweep of $G^{\prime}$ and $G^{\prime \prime}$ from 0.1 to $100 \mathrm{rad} / \mathrm{s}$ at various temperatures ranging from $-20{ }^{\circ} \mathrm{C}$ to $0{ }^{\circ} \mathrm{C}$ for the sample with $C_{\mathrm{P}}$ of $1.98 \mathrm{~mol} / \mathrm{L}$. At $0{ }^{\circ} \mathrm{C}, G^{\prime}$ is smaller than $G^{\prime \prime}$ and the power law exponents for $G^{\prime}$ and $G^{\prime \prime}$ against $\omega$ are very close to 2 and 1, respectively, indicating a terminal relaxation behavior. By cooling the sample to $-5{ }^{\circ} \mathrm{C}$, both dynamic moduli, especially $G^{\prime}$, exhibit sharp increase, and a crossover point of $G^{\prime}$ and $G^{\prime \prime}$ appears. We estimate the $\tau_{\mathrm{L}}$ as the inverse of the crossover frequency. The crossover frequency shifts to lower $\omega$ with decreasing temperature, suggesting an increase in the network relaxation time (Figure $\mathbf{2 b}$ ). When the temperature reaches to $-20{ }^{\circ} \mathrm{C}, G^{\prime}$ is larger than $G^{\prime \prime}$ over the measured frequency range and both 
moduli show weak frequency dependence, indicating a rubber-like solid behavior at the observation time window. Samples with other polymer concentrations show similar rheology behavior (Figure S5).

(a)

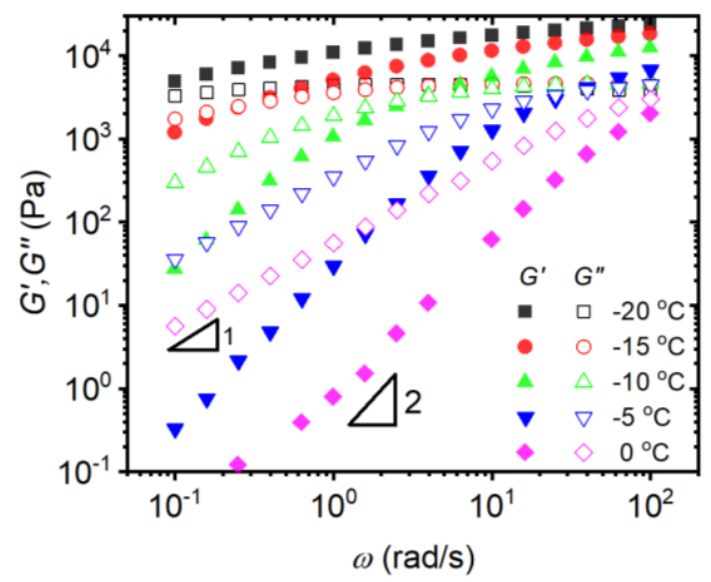

(b)

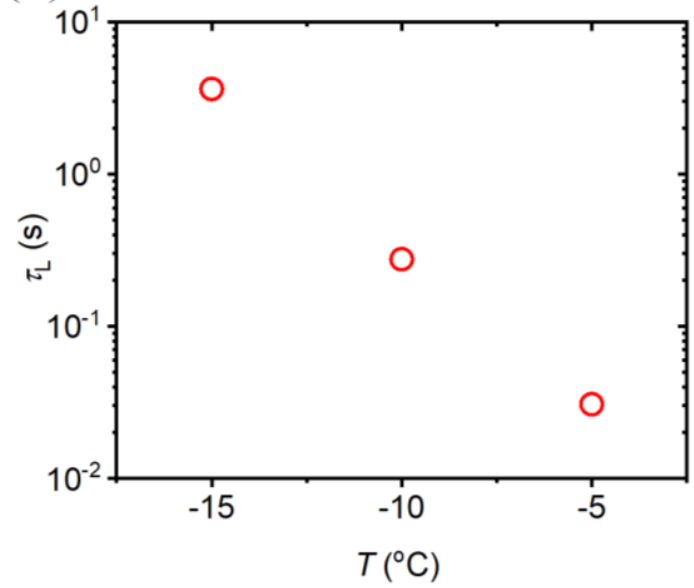

Figure 2. (a) Frequency dependence of storage modulus $G^{\prime}$ (filled) and loss modulus $G^{\prime \prime}$ (unfilled) for triblock copolymer/DMF at various temperatures. The maximum strain used in rheological test is $0.5 \%$ and the $C_{\mathrm{P}}$ is $1.98 \mathrm{~mol} / \mathrm{L}$. (b) Temperature dependence of the longest relaxation time $\tau_{\mathrm{L}}$. $\tau_{\mathrm{L}}$ is determined from the crossover frequency of $G^{\prime}$ and $G^{\prime \prime}$ by the equation $\tau_{\mathrm{L}}=1 / \omega$.

The network relaxation time of gel $\tau_{\mathrm{L}}$ is not only affected by temperature, but also affected by $C_{\mathrm{P}}$. Figure 3 summarizes the temperature dependence of $\tau_{\mathrm{L}}$ with $C_{\mathrm{P}}$ ranging from 0.91 to $2.09 \mathrm{~mol} / \mathrm{L}$. For all studied $C_{\mathrm{P}}$ where $\tau_{\mathrm{L}}$ could be determined, we found that $\tau_{\mathrm{L}}$ increases exponentially with increasing the inverse of temperature $1 / \mathrm{T}$. Interestingly, the slope for $\tau_{\mathrm{L}}$ against $1 / \mathrm{T}$ seems to be independent of $C_{\mathrm{P}}$, indicating the same energy barrier needed to overcome for relaxation. While $\tau_{\mathrm{L}}$ increases significantly with $C_{\mathrm{P}}$. For example, at same temperature of $-15^{\circ} \mathrm{C}\left(1 / \mathrm{T} \approx 3.88 \times 10^{-3} \mathrm{~K}^{-1}\right)$, increasing $C_{\mathrm{P}}$ from 1.14 to $2.09 \mathrm{~mol} / \mathrm{L}$ leads to an increase in relaxation time by more than 2 orders of magnitude. This indicates that the network connectivity increases with the polymer concentration. 


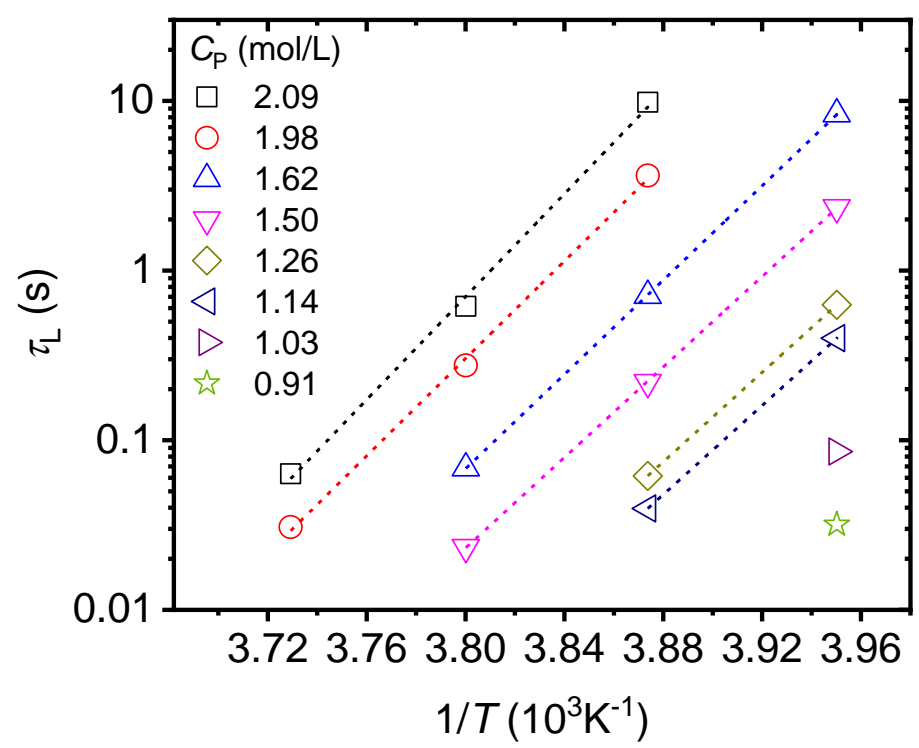

Figure 3. Temperature dependence of the longest relaxation time $\tau_{\mathrm{L}}$ of the system with various polymer concentrations $C_{\mathrm{P}}$.

Master curve and activation energy. Based on the above isothermal frequency sweep data collected over a wide range of temperatures, we constructed the master curve according to the time-temperature superposition (TTS) principle for different polymer concentrations $^{27,28}$. The reference temperature was set at $-20{ }^{\circ} \mathrm{C}$. For each polymer concentration, the frequency sweep curves were shifted horizontally with a temperature dependent shift factor $a_{\mathrm{T}}$, and no vertical shift was performed. Figure 4 shows a typical example with $C_{\mathrm{P}}$ of $1.98 \mathrm{~mol} / \mathrm{L}$. The curves of $G^{\prime}$ and $G^{\prime \prime}$ obtained at different temperature overlapped very well (Figure 4c). But the curve of $\ln a_{\mathrm{T}}$ verse $1 / \mathrm{T}$ shows two distinct linear regimes (Figure 4d), with an inflection temperature around $5{ }^{\circ} \mathrm{C}$. This indicates that different mechanisms govern the relaxation at temperatures above and below this critical temperature $T_{\mathrm{c}}$. From the temperature dependence of $a_{\mathrm{T}}$, the activation energy, $E_{\mathrm{a}}$, can be extracted from the following Arrhenius equation ${ }^{9,14}$ :

$$
a_{\mathrm{T}}=A e^{E \mathrm{a} / R T}
$$


The activation energy below $\left(E_{1 \mathrm{a}}\right)$ and above $\left(E_{2 \mathrm{a}}\right)$ the critical temperature $T_{\mathrm{c}}$ were determined as $249 \mathrm{~kJ} / \mathrm{mol}$ and $52 \mathrm{~kJ} / \mathrm{mol}$, respectively. A low activation energy above $T_{\mathrm{c}}$ suggests that the micelle structure is destroyed at high temperature regime.
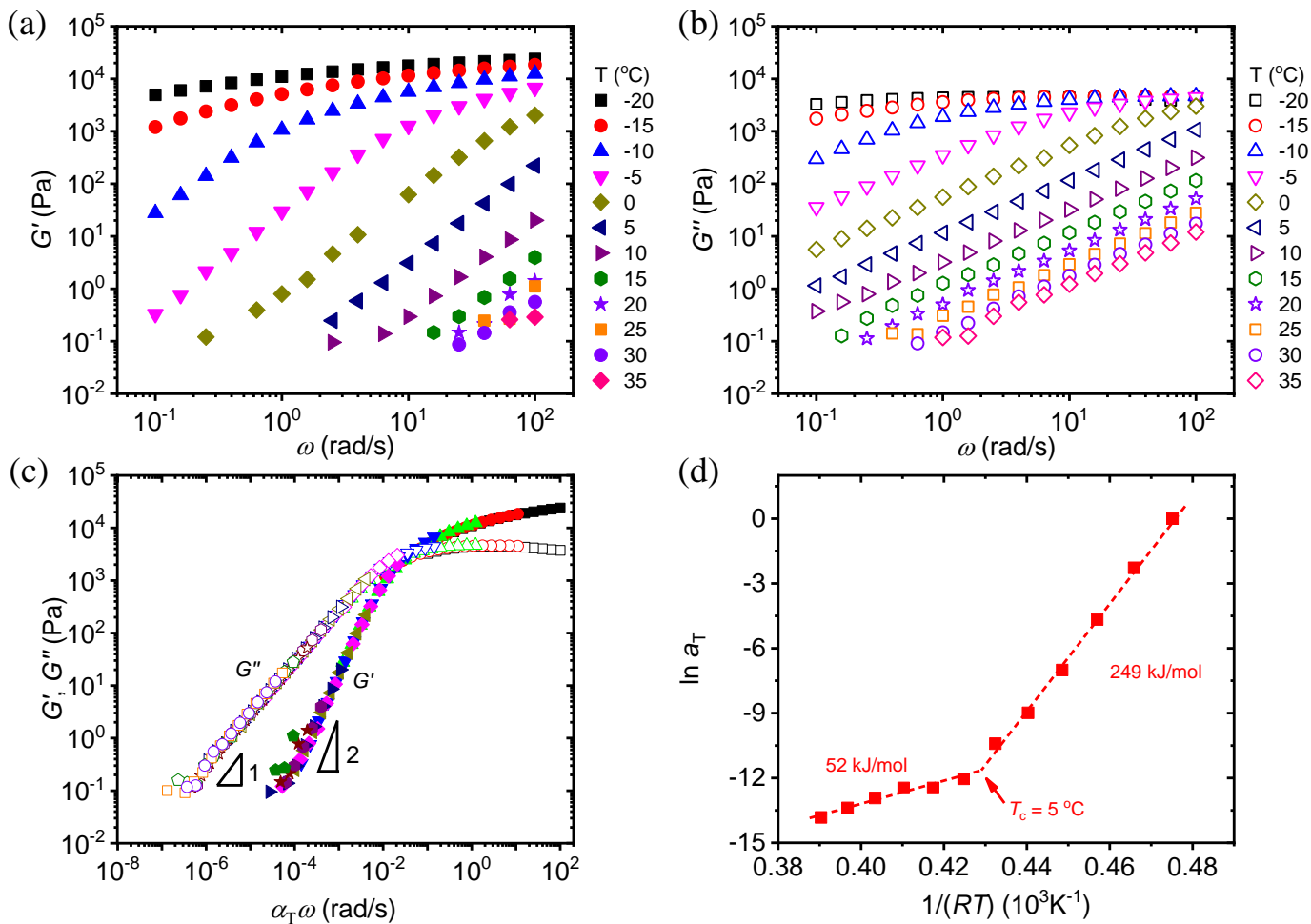

Figure 4. Frequency dependence of (a) storage moduli $G^{\prime}$ and (b) loss moduli $G^{\prime \prime}$ for triblock copolymer/DMF at different temperatures. The maximum strain used in rheological test is $0.5 \%$ and the $C_{\mathrm{P}}$ is $1.98 \mathrm{~mol} / \mathrm{L}$. (c) Time-temperature superposition master curves deduced from the data in (a-b) using horizontal shift factor $a_{\mathrm{T}}$. Reference temperature is set as $-20^{\circ} \mathrm{C}$. (d) Arrhenius plot depicting the temperature dependence of $a_{\text {T }}$ used to generate the master curves. The activation energies shown in the figure were calculated from the slopes of the curve. The slope changes at a critical temperature $5^{\circ} \mathrm{C}$.

Concentration dependence of relaxation dynamics. Samples with polymer concentrations $C_{\mathrm{P}}$ ranging from 0.91 to $2.21 \mathrm{~mol} / \mathrm{L}$ all show well-superposed time-temperature master curves (Figure S6). Similarly, all the plots of $\ln a_{\mathrm{T}}$ verse $1 / T$ show two linear regimes, with an inflection temperature around $5{ }^{\circ} \mathrm{C}$, independent of $C_{\mathrm{P}}$ (Figure 5a). The two activation energies, $E_{1 \mathrm{a}}$ and $E_{2 \mathrm{a}}$, below and above $5{ }^{\circ} \mathrm{C}$, respectively, are plotted as a function of $C_{\mathrm{P}}$ (Figure $\mathbf{5 b}$ ). The $E_{1 \mathrm{a}}$ is around $250 \mathrm{~kJ} / \mathrm{mol}$, almost 
independent of $C_{\mathrm{P}}$, while $E_{2 \mathrm{a}}$ increases from 12.8 to $101 \mathrm{~kJ} / \mathrm{mol}$ by increasing $C_{\mathrm{P}}$ from 0.91 to $2.21 \mathrm{~mol} / \mathrm{L}$. The independency of $E_{1 \mathrm{a}}$ with $C_{\mathrm{P}}$ indicates that $T_{\mathrm{c}}$ is the critical temperature for the micellization, since the energy gain for an end block in the micelle should only depend on its chemical structure and the interaction with the solvent, not on the polymer concentration ${ }^{1,13}$. More specifically, $E_{1 \mathrm{a}} \propto N^{2 / 3} \gamma$, where $N$ is the polymerization degree of the end block and $\gamma$ is the surface tension between the bulk end block polymers and solvent ${ }^{13,29}$. As $N$ and $\gamma$ do not change with $C_{\mathrm{P}}$, the concentration should have negligible effect on the $E_{1 \mathrm{a}}$. The increase of $E_{2 \mathrm{a}}$ with $C_{\mathrm{P}}$ also supports this explanation. Above $T_{\mathrm{c}}$, the end-block associations disappear, and sample is in sol state, so the activation energy $E_{2 a}$, which is the energy required to overcome the internal chain friction of entangled polymer solution that resists its flow, increases with polymer concentration $C_{\mathrm{P}}$. The value of $E_{1 \mathrm{a}}$ around $250 \mathrm{~kJ} / \mathrm{mol}$ is in the right range for transient networks ${ }^{14,29}$. The $C_{\mathrm{p}}$-independency of the activation energy $E_{1 \mathrm{a}}$ is in consistent with the results reported for PMAA- $b$-PBMA- $b$-PMAA in 2-ethylhexanol ${ }^{1}$ and $\mathrm{Br}$ $\mathrm{P}\left(\mathrm{nBMA} 50 \%\right.$-stat-tBMA50\%) ${ }_{101}-\mathrm{PtBMA}_{204}-\mathrm{P}\left(\mathrm{nBMA} 50 \%\right.$-stat-tBMA50\%) ${ }_{101}-\mathrm{Br} \quad$ in dichloromethane ${ }^{13}$.

(a)

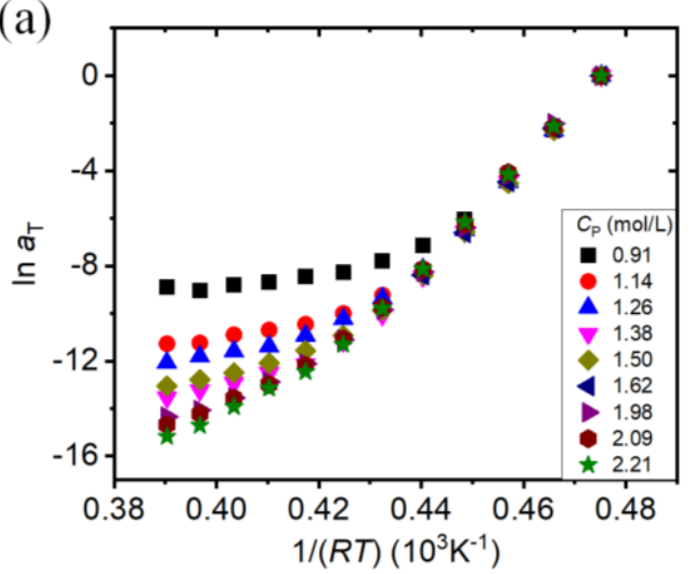

(b)

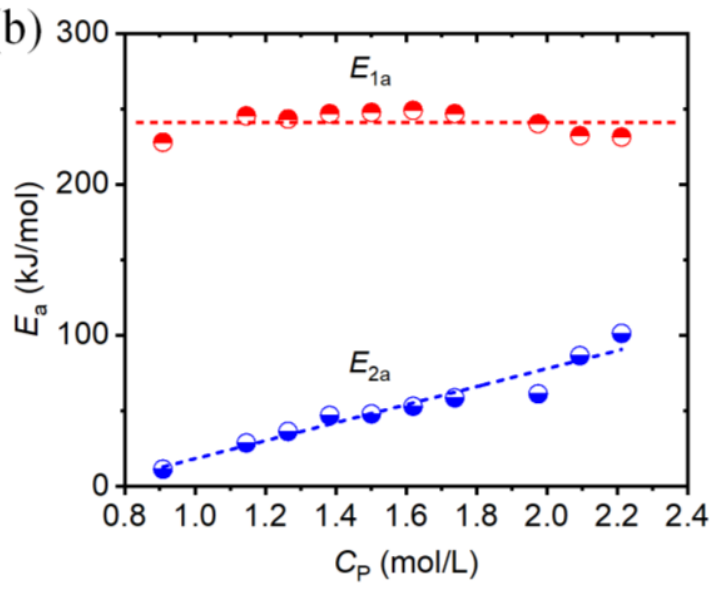

Figure 5. (a) Arrhenius plots depicting the temperature dependence of the shift factors $a_{\mathrm{T}}$ used for 
generating master curves in triblock copolymer/DMF with different $C_{\mathrm{P}}$. (b) The concentration dependence of activation energy in low temperature regime and high temperature regime.

From the temperature dependent $a_{\mathrm{T}}$, the longest relaxation time of the system at any given temperature can be obtained by the relation ${ }^{1,14,22}$ :

$$
\tau_{\mathrm{L}}=\tau_{\mathrm{L}, \mathrm{ref}} a_{\mathrm{T}}
$$

where $\tau_{\mathrm{L}, \text { ref }}$ is the longest relaxation time at the reference temperature. The sample with $C_{\mathrm{P}}$ of $1.98 \mathrm{~mol} / \mathrm{L}$ is used as an example to show the temperature dependence of relaxation time (Figure 6). The $\tau_{\mathrm{L}}$ obtained by this method is almost the same as that directly obtained from frequency sweep, but with much larger temperature range. For studied temperatures ranging from -20 to $35^{\circ} \mathrm{C}, \tau_{\mathrm{L}}$ changes from $2 \times 10^{-5} \mathrm{~s}$ to $2 \times 10^{1} \mathrm{~s}$, by 6 orders of magnitude. The increase of $\tau_{\mathrm{L}}$ with $1 / \mathrm{T}$ follows exponential relations, showing two distinct regimes. In low temperature regime, $\tau_{\mathrm{L}}$ increases more rapidly. The inflection temperature is around $5{ }^{\circ} \mathrm{C}$, in consistent with the inflection temperature for the activation energy change. Again, this result indicates that the micellization of the end blocks occurs at the critical temperature $T_{\mathrm{c}}=5^{\circ} \mathrm{C}$, which brings about the sol-gel transition. 


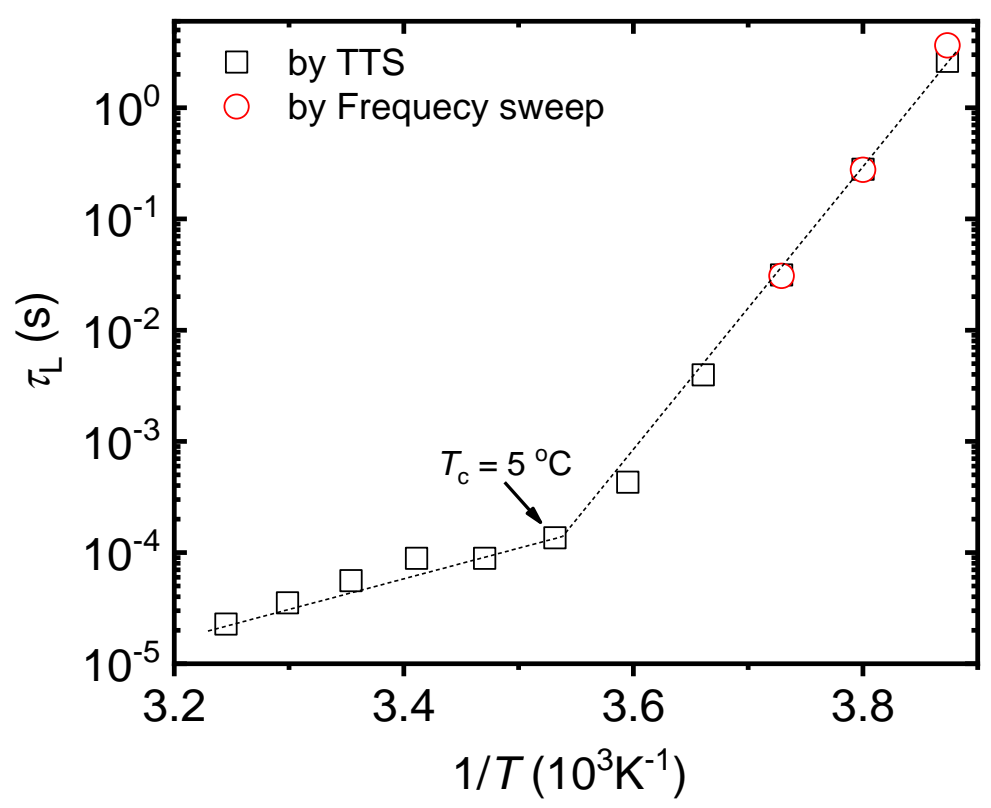

Figure 6. Temperature dependence of the longest relaxation time $\tau_{\mathrm{L}}$ for triblock copolymer/DMF $\left(C_{\mathrm{P}}\right.$ : $1.98 \mathrm{~mol} / \mathrm{L}$ ). The square corresponds to the data obtained from Eq.2 using shift factor $a_{\mathrm{T}}$ and $\tau_{\mathrm{L}, \text { ref }}$ at $-20{ }^{\circ} \mathrm{C}(\sim 20 \mathrm{~s})$, the sphere corresponds to the data obtained from frequency sweep at different temperatures. The inflection temperature $T_{\mathrm{c}}$ is around $5^{\circ} \mathrm{C}$.

Structure Analysis by SAXS and NMR. The temperature dependence of $a_{\mathrm{T}}, \tau_{\mathrm{L}}$ and $E_{\mathrm{a}}$ all suggest the formation of micelle structure below the critical temperature $T_{\mathrm{c}}=5{ }^{\circ} \mathrm{C}$, and different mechanisms governing the relaxation at temperature above and below $T_{\mathrm{c}}$. To analyze the micelle structure and its evolution with temperature change, we performed SAXS measurement at different temperatures for the sample with $C_{\mathrm{P}}$ of $1.98 \mathrm{~mol} / \mathrm{L}$. Figure 7 presents the 2D SAXS patterns at a temperature range of -20 to $25{ }^{\circ} \mathrm{C}$ and the corresponding 1D scattering profiles. At $-20^{\circ} \mathrm{C}$, an obvious scattering ring is observed, indicating the formation of a disordered array of micelles. The intensity of scattering ring decreases with increasing temperature below $5{ }^{\circ} \mathrm{C}$, suggesting the decrease in contrast between micelles and the surrounding environment. The scattering ring completely disappears above $5{ }^{\circ} \mathrm{C}$, suggesting that the micellar structure disappears and the system 
changes from micellar network to homogeneous solution. The critical temperature for structure transition just corresponds to the inflection temperature $T_{\mathrm{c}}$ defined by $a_{\mathrm{T}}, \tau_{\mathrm{L}}$ and $E_{\mathrm{a}}$. Therefore, the transient network crosslinked by micelles dominates the relaxation behavior at temperature below $T_{\mathrm{c}}$, while the entangled polymer solution dominates the relaxation behavior above $T_{\mathrm{c}}$. This leads to the two-stage temperature dependence of $a_{\mathrm{T}}$ and $\tau_{\mathrm{L}}$

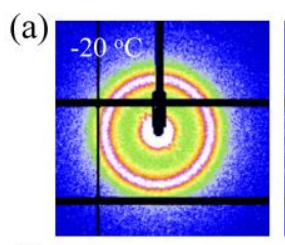

(b)

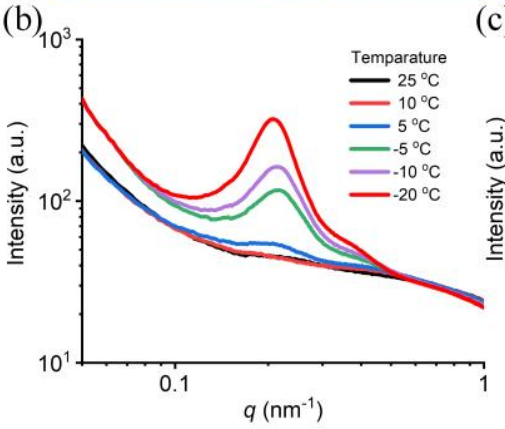

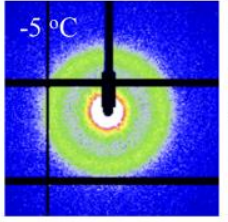

(c)
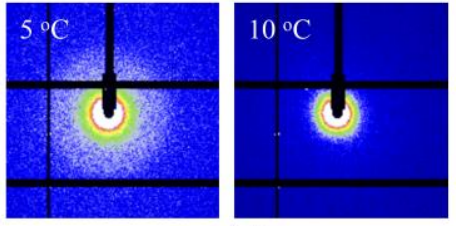

(d)
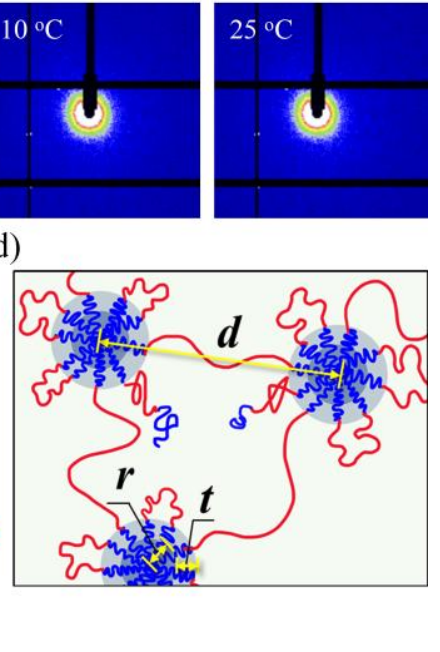

Figure 7. (a) Selected 2D small-angle $\mathrm{X}$-ray scattering patterns of triblock copolymer/DMF at different temperatures and (b) the corresponding $1 \mathrm{D}$ scattering intensity profiles $\left(C_{\mathrm{P}}: 1.98 \mathrm{~mol} / \mathrm{L}\right) .(\mathrm{c})$ The fitting curve for the triblock copolymer/DMF at $-20^{\circ} \mathrm{C}$. The solid line is the fitting result using the core-shell model with hard sphere repulsions. (d) The illustration of the molecular structure of the transient networks. $r, t$ and $d$ represent the radius of hard-core, the thickness of soft shell, and center-to-center distance between neighboring micelles, respectively.

The SAXS results provide detailed structure information of micellar network. The 1D scattering profile has an obvious scattering peak at $q$ around $0.2 \mathrm{~nm}^{-1}$ and a weak shoulder after the peak. The former is from the correlation between micelles and the latter is from the structure of micelle. As the shoulder is rather weak at temperature higher than $-15^{\circ} \mathrm{C}$, only the correlation between micelles, that is, the average center-to-center distance, $d$, between adjacent micelles was calculated, with the equation $d=2 \pi / q_{\text {peak. }}$. Here $q_{\text {peak }}$ is 
peak position of the first peak. The $d$ keeps almost constant $(\sim 30 \mathrm{~nm})$ with decreasing temperature, suggesting that the structure of micellar network has negligible change with temperature once it formed. The scattering profile at $-20^{\circ} \mathrm{C}$ can be well fitted with the core-shell model with hard sphere repulsions (Figure 7c) and gives the structure information of micelles. This model has been widely used in block copolymer systems and the details of this model can be found in literatures ${ }^{30-33}$. Figure $7 \mathbf{d}$ displays the structural representation for the gels. The end blocks form micelles and a polymer chain of its two end blocks in different micelles (bridging chain) contributes to elasticity of the network, while a polymer chain of its two end blocks in same micelles (loop) or only one end block in micelle does not form network. Each micelle has a dense core with a radius $r$, surrounded by an outer shell with a thickness of $t^{32}$. From the fitting, the average center-to-center distance, $d$, and four parameters of micelles, $r, t, \eta$ and $(\Delta r) / r$, can be obtained. Here $\eta$ is the volume fraction of micelles, and $(\Delta r) / r$ is standard deviation over the mean value $r$, representing the distribution of hard-core radius $r$. For the sample with $C_{\mathrm{P}}$ of $1.98 \mathrm{~mol} / \mathrm{L}$ at $-20{ }^{\circ} \mathrm{C}, r, t, \eta$ and $(\Delta r) / r$ are $7.9 \mathrm{~nm}, 4.1 \mathrm{~nm}, 0.26$ and 0.50 , respectively. The relatively large $(\Delta r) / r$ should be attributed to polydispersity of the triblock copolymer (Table 1).

As the end blocks have a short lifetime, they are exchangeable between micelles. The attachment and detachment of end blocks from micelles reach a dynamic equilibrium. The mid blocks with two attached end blocks act as bridges or loops, while the mid blocks with only one attached end block act as dangling chains before next attachment. To get the fraction of dangling chain, ${ }^{1} \mathrm{H}$ NMR was carried out at different temperatures. The 
molecular structure of triblock copolymer and the proton NMR spectra were shown in Figure 8a and $\mathbf{8} \mathbf{b}^{34,35}$, respectively. The characteristic peak of methylene groups in end block, name as peak 1, is around $4.2 \mathrm{ppm}$. At high temperature, the end blocks are un-associated, and the peak intensity is high. With decreasing temperature, end blocks associate into micelles, and the number of un-associated end blocks decreases, leading to a decrease in peak intensity. Therefore, this peak can be used to estimate the fraction of un-associated end blocks. The peak area, represents the number of un-associated end blocks, was normalized by the standard peak of DMF (peak 9) to remove the effect of temperature $^{36}$. The normalized peak area $\mathrm{S}_{\mathrm{n}}(\mathrm{T})=S_{\text {peak } 1} / S_{\text {peak9 } 9}$ is temperature dependent (Figure S7). Here we take the sample with $C_{\mathrm{P}}$ of $1.98 \mathrm{~mol} / \mathrm{L}$ to show this temperature dependence (Figure 8c). At high temperature, $\mathrm{S}_{\mathrm{n}}(\mathrm{T})$ almost does not change with the temperature. Below $20{ }^{\circ} \mathrm{C}, \mathrm{S}_{\mathrm{n}}(\mathrm{T})$ decreases dramatically with temperature until about $0{ }^{\circ} \mathrm{C}$, and then decreases very weakly. NMR result suggests that association between end blocks starts from $20{ }^{\circ} \mathrm{C}$, while the micelle formation starts effectively at $5{ }^{\circ} \mathrm{C}$, as demonstrated by the SAXS and rheological results. Assuming all the end blocks are un-associated at plateau region (high temperatures), the fraction of un-associated end blocks at different temperature can be calculated from $f_{\text {dangling }}=S_{n}(T) / S_{n \text {,plateau, where }} S_{n \text {,plateau }}$ is the normalized peak area at plateau regime. As shown in Figure 8c, even at temperature of $-20{ }^{\circ} \mathrm{C}$, the fraction of un-associated end blocks, or dangling end blocks $f_{\text {dangling }}$, is as high as $12 \%$, which is not negligible. 
(a)

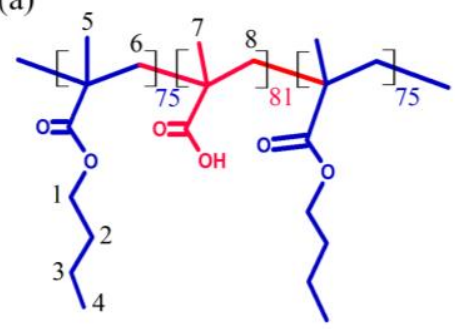

(b)

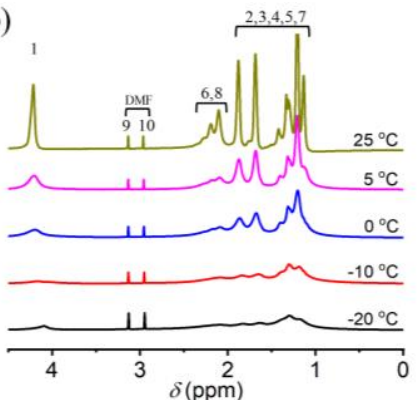

(c)

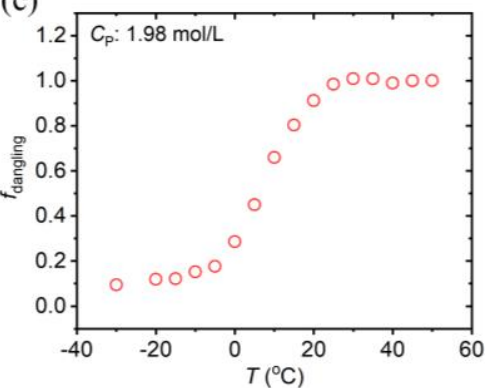

Figure 8. (a) Chemical structures of the triblock copolymers. The $H$ atoms were coded for NMR peak assignments. (b) ${ }^{1} \mathrm{H}$ NMR spectra of triblock copolymer/DMF at different temperatures $\left(C_{\mathrm{P}}: 1.98\right.$ $\mathrm{mol} / \mathrm{L}$ ). The numbers in the spectra are assigned to protons shown in (a). (c) Temperature dependence of dangling fraction of end blocks at $C_{\mathrm{P}}=1.98 \mathrm{~mol} / \mathrm{L}$.

With the fraction of dangling end blocks, we can calculate the aggregation number of end blocks in a micelle, $N_{\mathrm{g}}{ }^{1,11}$, with methods shown in Supporting Information. $N_{g}$ has a slightly decrease from 252 to 216 by increasing temperature from -20 to $-5{ }^{\circ} \mathrm{C}$. As both $d$ and $N_{g}$ show almost no or slightly change with temperature, the substantial increase of the scattering intensity in Figure $\mathbf{7 b}$ should be attributed to the increased density contrast between micelles and the surrounding environment. That means, PBMA micelles deswell with decreasing temperature by expelling solvent from micelles. These results reveal the self-assembly process of micellar network. At temperature above $T_{\mathrm{c}}=5{ }^{\circ} \mathrm{C}$, the triblock copolymers dissolve homogeneously in DMF. With decreasing temperature, the end blocks associate into micelles, which bridged by mid blocks and form a transient network. Further decreasing temperature, the structure of micellar network has negligible change while the micelles shrink, because the solvent quality for the end blocks worsens and a part of solvent is expelled from the micelles ${ }^{14,37}$. The change in solvent quality (or temperature) influences the exchange dynamic of end blocks, leading to the exponential increase of network relaxation time of gel upon cooling (Figure $2 b$ and Figure 3 ). This 
argument is also supported by the results reported by Tsitsilianis et al. ${ }^{22}$. They tuned the lifetime of end block associations and found that the relaxation time of gel network strongly depends on the lifetime of end block associations.

The volume fraction of solvent in a micelle, $\varphi_{\text {sol }}$, can be calculated with the parameters $r, t$ and $N_{g}$ (Supporting Information). The $N_{g}$ of sample with $C_{\mathrm{P}}$ of 1.98 mol/L at $-20^{\circ} \mathrm{C}$ gives a PBMA volume of $3752.5 \mathrm{~nm}^{3}$ (Supporting Information), which is larger than the volume occupied by hard core $\left(4 / 3 \pi r^{3}=2064.2 \mathrm{~nm}^{3}\right)$. This suggests that both hard core and shell regions are occupied by end blocks. Thus, $\varphi_{\text {sol }}$ can be roughly estimated by the volume ratio of the end blocks themselves to the sum of core and shell. Even at lowest temperature of $-20{ }^{\circ} \mathrm{C}$ studied in our work, $\varphi_{\text {sol }}$ is still as high as 0.48 , which explains why the end blocks have a limited lifetime in micelle and the micellar network is transient.

Concentration effect on relaxation of whole network. As mentioned above, the transient network below the critical temperature for the micellization $\left(T_{\mathrm{c}}=5{ }^{\circ} \mathrm{C}\right)$ possess two important relaxations: the relaxation of end block and the relaxation of whole network. The relaxation of end block, characterized by the lifetime of end block in micelle, $\tau_{\mathrm{p}}$, is not in the dynamic spectrum window of this work, while the relaxation of whole network can be characterized by the network relaxation time $\tau_{\mathrm{L}}$, and it is strongly dependent on $C_{\mathrm{P}}$. Figure 9 presents the evolution of $\tau_{\mathrm{L}}$ as a function of $C_{\mathrm{P}}$ at $-20{ }^{\circ} \mathrm{C}$. The $\tau_{\mathrm{L}}$ increases sharply with increasing $C_{\mathrm{P}}$, following a strong power law relationship $\tau_{\mathrm{L}} \propto$ $C_{\mathrm{P}}{ }^{7.6}$. This exponent is much larger than the predicted value for the ideally entangled 
Gaussian chains: $\tau_{\mathrm{L}} \propto C_{\mathrm{P}}{ }^{1.5} \cdot{ }^{38-40}$ To reveal the possible reason, we performed SAXS measurement for samples with different $C_{\mathrm{P}}$ from 0.79 to $1.5 \mathrm{~mol} / \mathrm{L}$ at $-20{ }^{\circ} \mathrm{C}$ (Figure 10). The peak position $q_{\text {peak }}$ shifts to large value with increasing $C_{\mathrm{P}}$, suggesting that the number density of micelles increases with $C_{\mathrm{P}}$. The NMR results show that the fraction of dangling chains hardly changes with the polymer concentration $C_{\mathrm{P}}$ at the low temperature regime (Figure S7). With the aforementioned method, the aggregation number $N_{\mathrm{g}}$ was calculated, which increase from 170 to 252 by increasing $C_{\mathrm{P}}$ from 1.03 to $1.98 \mathrm{~mol} / \mathrm{L}$.

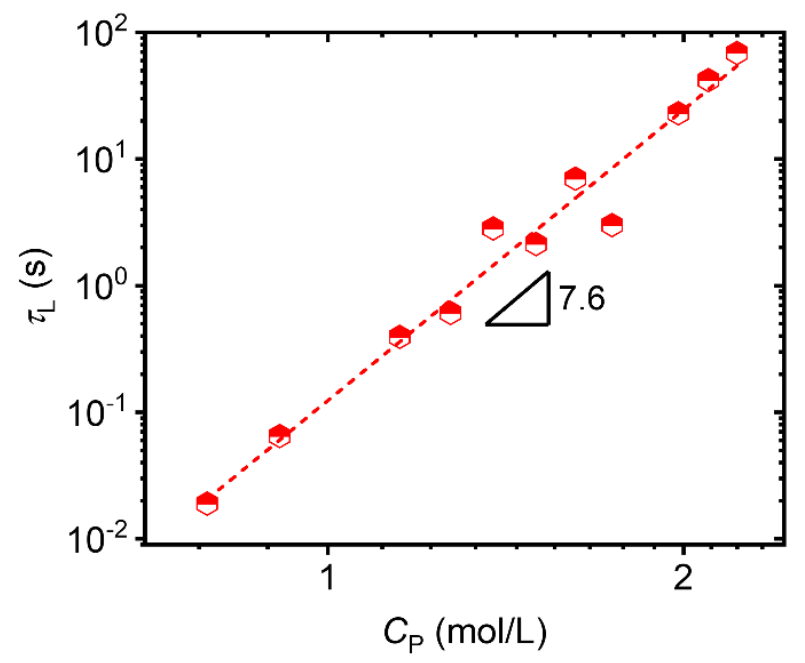

Figure 9. Polymer concentration $C_{\mathrm{P}}$ dependence of the longest relaxation time $\tau_{\mathrm{L}}$. Temperature: -20 ${ }^{\circ} \mathrm{C}$.
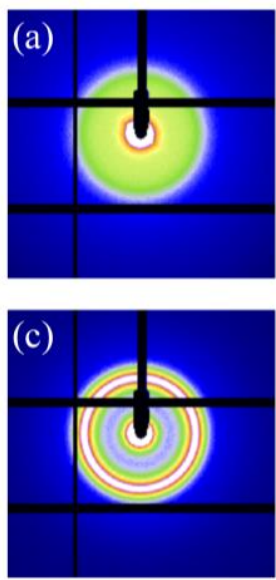

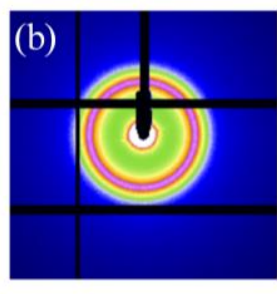

(d)

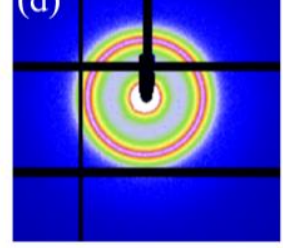

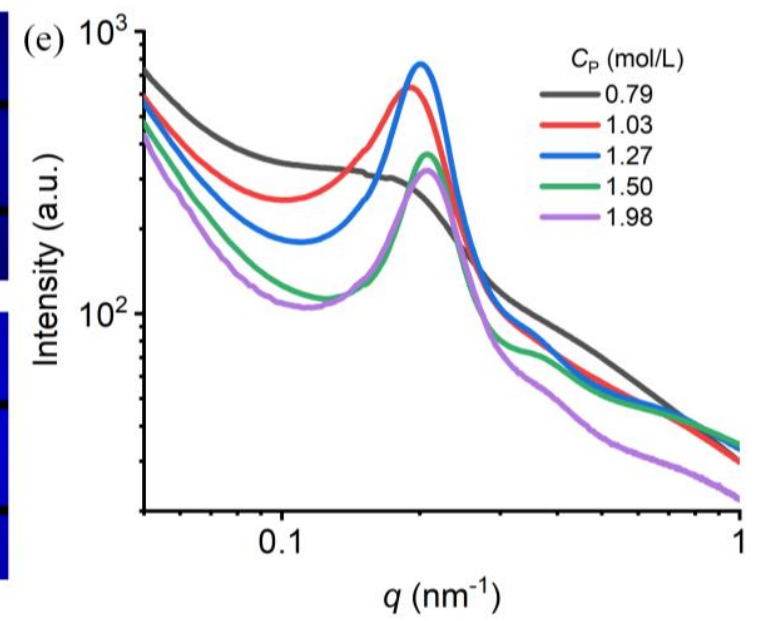

Figure 10. 2D small-angle $X$-ray scattering patterns of triblock copolymer/DMF with polymer concentrations $C_{\mathrm{P}}$ of (a) $0.79 \mathrm{~mol} / \mathrm{L}$, (b) $1.03 \mathrm{~mol} / \mathrm{L}$, (c) $1.27 \mathrm{~mol} / \mathrm{L}$ and (d) $1.50 \mathrm{~mol} / \mathrm{L}$ (temperature: 
$-20^{\circ} \mathrm{C}$ ). (e) The corresponding integrated 1D SAXS intensity profiles. The 1D SAXS intensity profile for $1.98 \mathrm{~mol} / \mathrm{L}$ at $-20{ }^{\circ} \mathrm{C}$ is also shown for better comparison.

With the increase of $C_{\mathrm{P}}$ and number density of micelles, the probability to form bridges increases. The increase in bridge number or bridge fraction unambiguously increases the relaxation time of network and shear modulus due to the increased connectivity of the network. The bridge fraction of transient network can be quantitatively evaluated from plateau modulus $G_{\mathrm{N}}$, assuming that $G_{\mathrm{N}}$ is from the network structure formed by bridged micelles and there are no topological entanglements between loops. Assuming that the mid blocks are in Gaussian chain conformation, the transient network theory predicts that the plateau modulus is given by $G_{\mathrm{N}}=v_{0} f k T$, where $v_{0}$ is the number density of polymer chain and it is proportional to $C_{\mathrm{P}}, f$ is the fraction of elastically effective chain ${ }^{41}$. In our case, $v_{0}$ is the number density of mid blocks, and the elastically effective chain is the bridges formed by mid blocks between neighboring micelles. These two assumptions are reasonable, because 1) the molecular weight of midblock is smaller than the entanglement molecular weight $\left(7500 \mathrm{~g} \mathrm{~mol}^{-1}\right)^{42}$, hence the entanglement effect is negligible; 2) the fast relaxation dynamics of crosslinker (micelle) of the transient network make the bridged chains staying in stress free state and thus taking Gaussian conformation; 3) the high multi-functional crosslinking point gives the affine deformation. As shown in Figure S6, all the master curves show a plateau at high frequency followed by terminal relaxation at low frequency. Since $G^{\prime}$ in the plateau region is not strictly horizontal, $G_{\mathrm{N}}$ was determined as two times of crossover modulus based on simple Maxwell model ${ }^{43}$. The concentration dependence of $G_{\mathrm{N}}$ is plotted in Figure 11a. As $C_{\mathrm{P}}$ increases, $G_{\mathrm{N}}$ first increased sharply and then showed a linear increase 
at high $C_{\mathrm{P}}$.

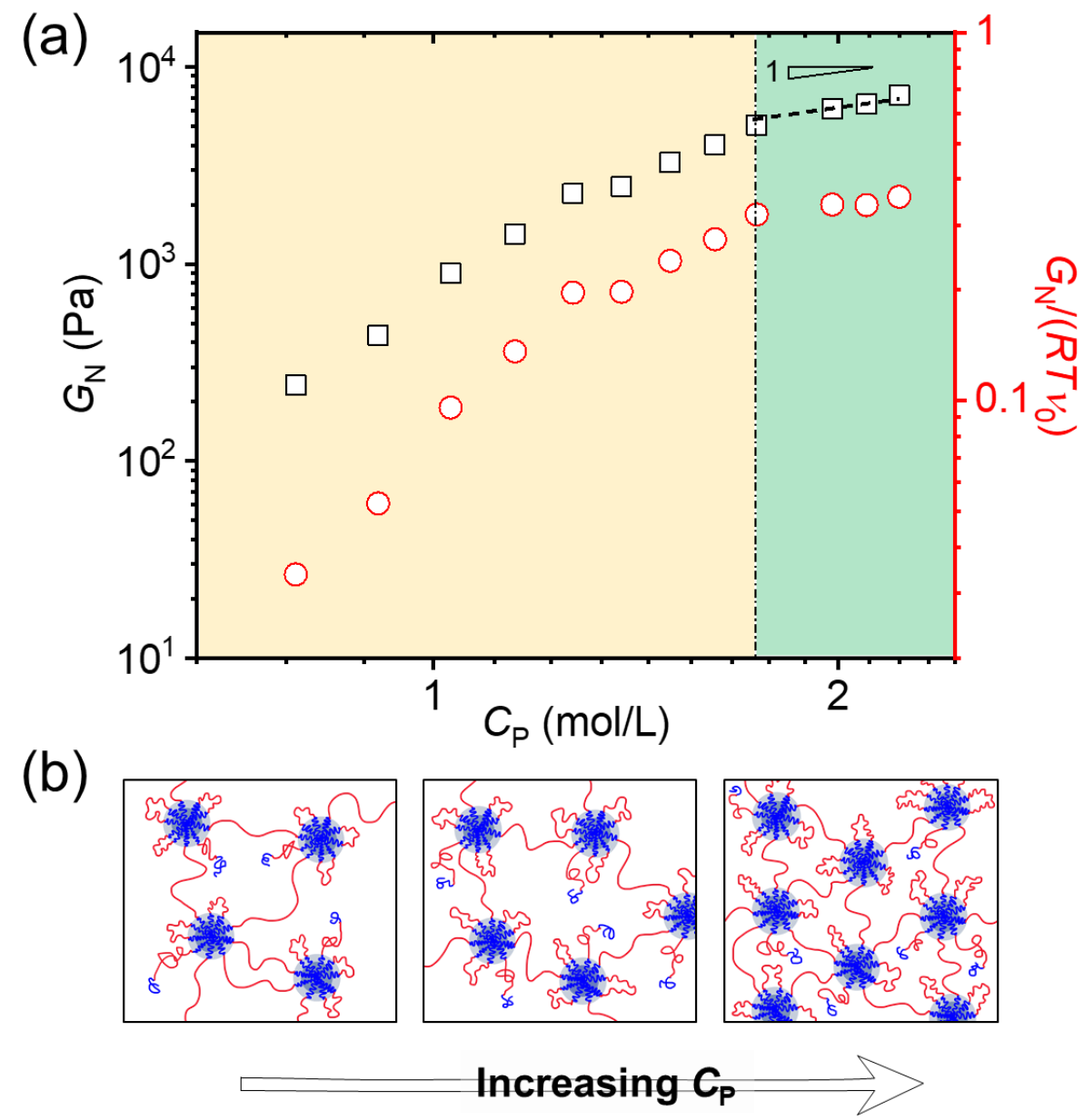

Figure 11. (a) Concentration dependence of plateau modulus $G_{\mathrm{N}}$ and bridging chain fraction $f$ calculated by $G_{\mathrm{N}} /\left(R T v_{0}\right)$. Temperature: $-20^{\circ} \mathrm{C}$. The dash line stands for a slope of one. (b) Schematic illustrations of the structure evolution as increasing concentration. The PBMA end blocks are in blue, and the solvophilic PMAA mid blocks are in red.

For a fully developed network, where all mid blocks act as effective chains, $G_{\mathrm{N}}$ should be proportional to $C_{\mathrm{P}}$. To make it clearer, $G_{\mathrm{N}}$ is normalized by $R T v_{0}$ and plotted as a function of $C_{\mathrm{P}}{ }^{13,44}$. The normalized quantity $G_{\mathrm{N}} / R T v_{0}$ first increases quickly with $C_{\mathrm{P}}$ and then reaches a plateau, suggesting the fraction of bridged chains first increases with concentration and then becomes saturated. This means that at low concentration, the network contains many defects, many end blocks are in loop state and some in dangling state that do not contribute to elasticity of the gel (Figure 11b). With the increase in the 
polymer concentration, the fraction of loops decreases and a relatively perfect network with saturated bridge fraction is formed. Such trend is in consistent with the prediction of dissipative particle dynamics model. ${ }^{10}$ From the modulus data, the saturated bridge fraction at high concentration is around 0.4 for our gels. Since the dangling fraction for this sample at $-20{ }^{\circ} \mathrm{C}$ is 0.12 , the loop fraction is estimated as 0.48 in the plateau region.

Time-concentration superposition (TCS). In analogy to the TTS, the time-concentration superposition (TCS) has also been utilized to study the relaxation behaviors of triblock copolymer/DMF system. Figure 12a and 12b shows an example of $G^{\prime}$ and $G^{\prime \prime}$ for samples with different concentrations measured at $-20{ }^{\circ} \mathrm{C}$ using the data obtained at $2.21 \mathrm{~mol} / \mathrm{L}$ as a reference concentration. Remarkably, all the data superimpose into a master curve, which is presented in Figure 12c based on the horizontal shift factor $a_{\mathrm{C}}$ and vertical shift factor $b_{\mathrm{C}}$ shown in Figure 12d.

Furthermore, the TCS were performed at various temperature with $C_{\mathrm{P}}$ of $2.21 \mathrm{~mol} / \mathrm{L}$ as a reference concentration (Figures S8 and S9). The master curves at different temperatures show a similar shape. At low temperature, $G^{\prime}$ and $G^{\prime \prime}$ intersect, giving the longest relaxation time $\tau_{\mathrm{L}}$ (Figure S8). At high temperature, $\tau_{\mathrm{L}}$ cannot be directly obtained as only terminal region was observed due to the fast dynamic of the sample at sol state. To get more insight into the relaxation dynamics of the TCS process, the $\tau_{\mathrm{L}}$ at high temperature was estimated by fitting the dynamic moduli with single-mode Maxwell model (Figure S9). 

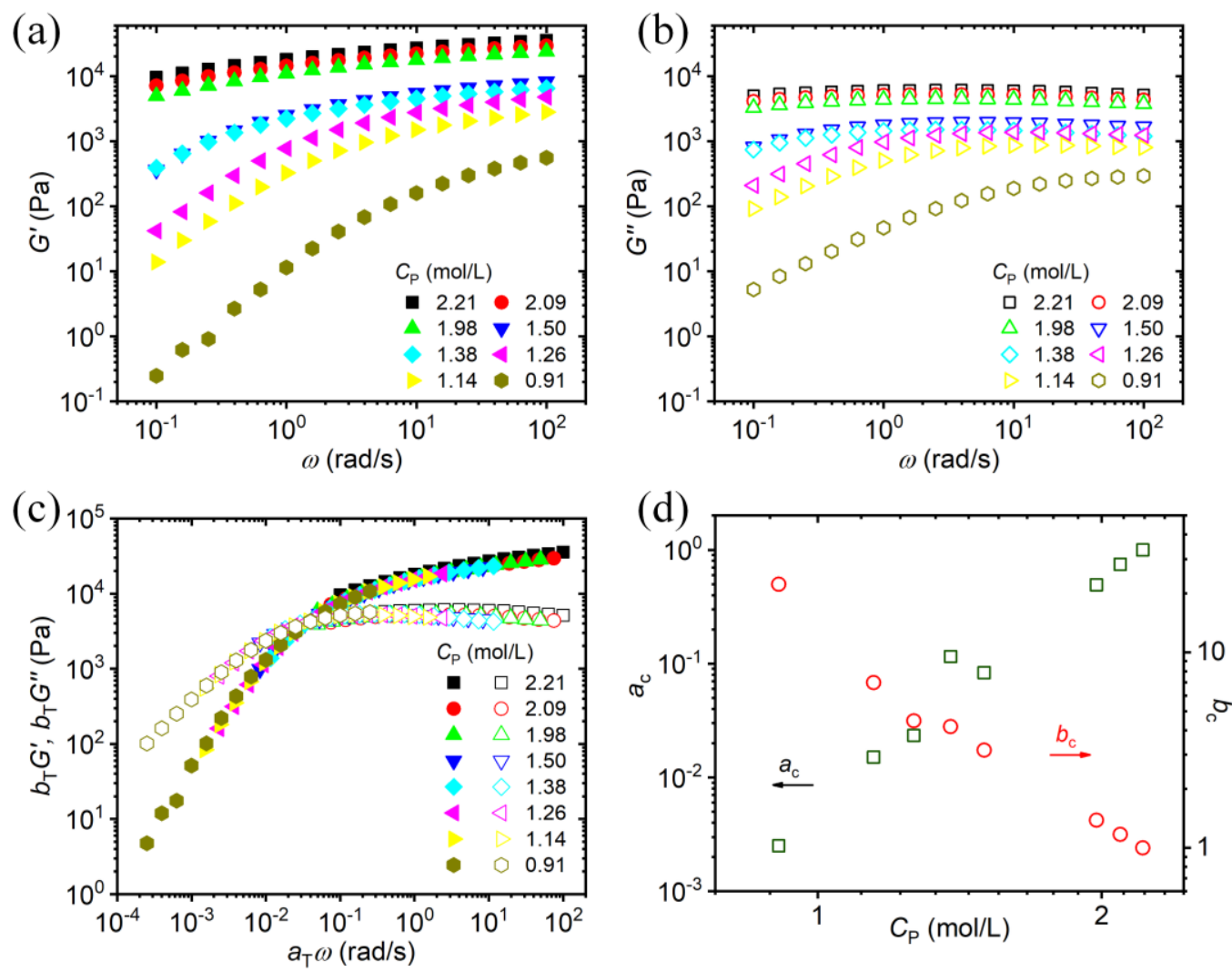

Figure 12. Frequency dependence of storage modulus $G^{\prime}$ (a) and loss modulus $G^{\prime \prime}$ (b) for triblock copolymer/DMF with different concentrations at $-20^{\circ} \mathrm{C}$. (c) Master curves at $-20{ }^{\circ} \mathrm{C}$ deduced from the data in (a) using horizontal shift factor $a_{\mathrm{C}}$ and vertical shift factor $b_{\mathrm{C}}$ (Reference concentration: 2.21 $\mathrm{mol} / \mathrm{L}$ ). (d) Concentration dependence of horizontal shift factor $a_{\mathrm{C}}$ and vertical shift factor $b_{\mathrm{C}}$ used for generating the time-concentration superposition master curves at $-20{ }^{\circ} \mathrm{C}$.

The longest relaxation time $\tau_{\mathrm{L}}$ obtained by combing the TTS and Eq. (2) is plotted against $\tau_{\mathrm{L}}$ determined by combing the TCS and the fitting with single-mode Maxwell model (Figure 13). It is remarkable that $\tau_{\mathrm{L}}$ determined with above two methods agrees pretty good. This agreement suggests that the relaxation behaviors have the same qualitative temperature or concentration dependence. In such case, the relaxation times are related through a shift factor $a_{T}$ or $a_{\mathrm{C}}$. As $a_{T}$ and $a_{\mathrm{C}}$ are also concentration and temperature dependent, respectively, they can be expressed as $a_{T}(\mathrm{C})$ and $a_{\mathrm{C}}(\mathrm{T})$. Accordingly, the more general form of temperature or concentration dependence of longest relaxation time is $\tau_{\mathrm{L}}\left(T, C_{r e f}\right)=\tau_{\mathrm{L}}\left(T_{r e f}, C_{r e f}\right) \times a_{T}\left(C_{r e f}\right)$ or $\tau_{\mathrm{L}}\left(T_{r e f}, C\right)=\tau_{\mathrm{L}}\left(T_{r e f}\right.$, 
$\left.C_{r e f}\right) \times a_{\mathrm{C}}\left(\mathrm{T}_{r e f}\right)$, where $\tau_{\mathrm{L}}\left(T, C_{r e f}\right)$ and $\tau_{\mathrm{L}}\left(T_{r e f}, C\right)$ are the longest relaxation time at arbitrary temperature $T$ for a reference concentration $C_{\text {ref }}$ and the longest relaxation time at arbitrary concentration $C$ for a reference temperature $T_{\text {ref, }}$ respectively. The $a_{T}\left(C_{r e f}\right)$ and $a_{\mathrm{C}}\left(\mathrm{T}_{r e f}\right)$ are the parallel shift factors of TTS at reference concentration and of TCS at reference temperature, respectively. The $\tau_{\mathrm{L}}\left(T_{r e f}, C_{r e f}\right)$ referred as the relaxation time at reference temperature and concentration. The temperature and concentration exchangeable relationship permits us to estimate the longest relaxation time $\tau_{\mathrm{L}}$ at any temperature and concentration, from a given reference longest relaxation time as well as the shift factors $a_{\mathrm{T}}$ and $a_{\mathrm{C}}$ by a two-step process (Figure 14). For example, we can first fix the concentration at the reference state $C_{\text {ref }}$ and change the temperature from $T_{\text {ref }}$ to $T$, then, keep the temperature at $T$ and change the concentration from $C_{\text {ref }}$ to $C$. Following this process, the equation of $\tau_{\mathrm{L}}(T, C)=\tau_{\mathrm{L}}\left(T_{r e f}, C_{r e f}\right) \times a_{T}\left(C_{r e f}\right) \times a_{\mathrm{C}}(T)$ can be obtained. We can also first fix the temperature at the reference state $T_{\text {ref }}$ and change the concentration from $C_{\text {ref }}$ to $C$, then, keep the concentration at $C$ and change the temperature from $T_{\text {ref }}$ to $T$. By this process, we can have $\tau_{\mathrm{L}}(T, C)=\tau_{\mathrm{L}}\left(T_{r e f}, C_{r e f}\right) \times a_{\mathrm{C}}\left(T_{r e f}\right)$ $\times a_{T}(C)$. Using the data shown in Table $\mathbf{S 2}$ and Table S3, we can obtain $\tau_{\mathrm{L}}(T, C)$ at any given $T$ and $C$. 


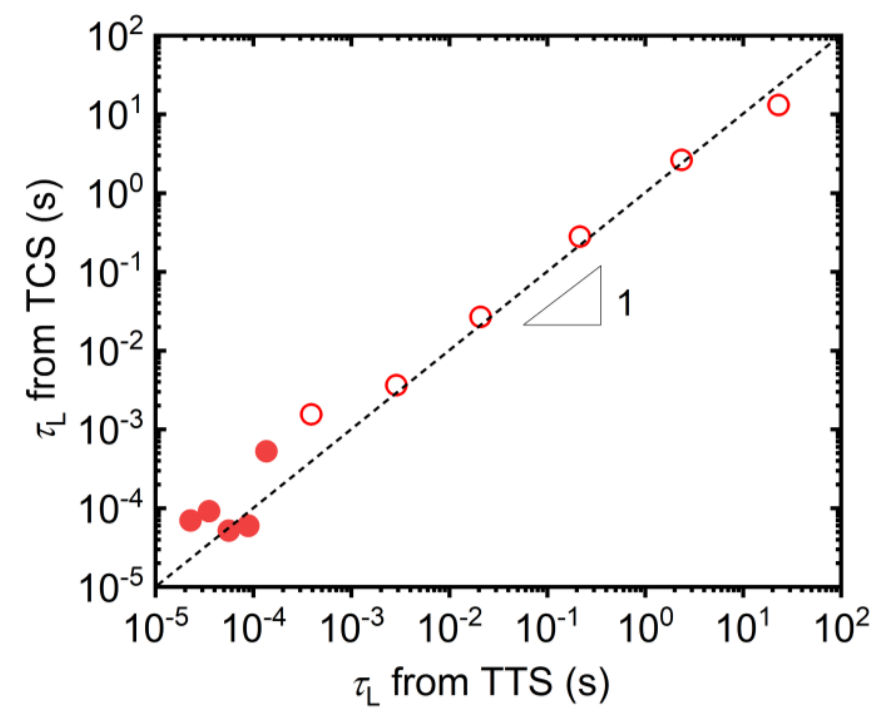

Figure 13. Plot of longest relaxation time $\tau_{\mathrm{L}}$ determined from TTS against $\tau_{\mathrm{L}}$ obtained from TCS. The unfilled red sphere corresponds to $\tau_{\mathrm{L}}$ below $T_{\mathrm{c}}$ (gel state) and the filled red sphere corresponds to $\tau_{\mathrm{L}}$ above $T_{\mathrm{c}}$ (sol state). The dash line stands for a slope of one.

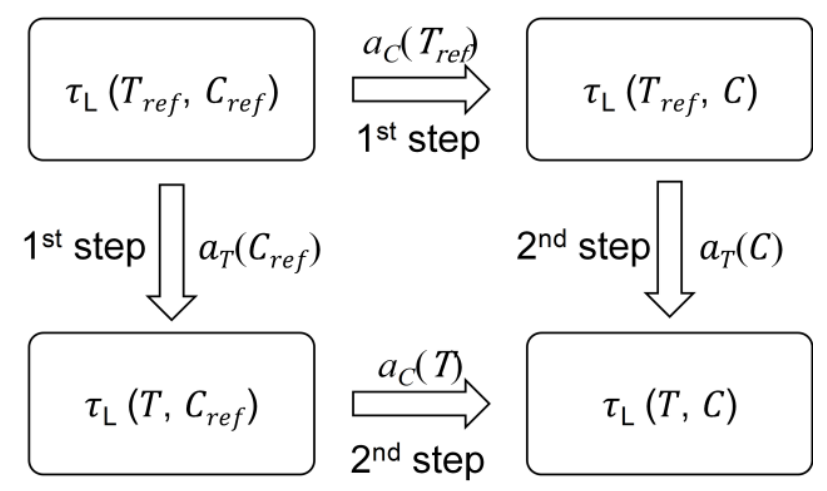

Figure 14. Schema of two-step method for estimating the longest relaxation time $\tau_{\mathrm{L}}$ at any temperature and concentration from a given reference longest relaxation time $\tau_{\mathrm{L}}\left(T_{r e f}, C_{r e f}\right)$ as well as the shift factors $a_{\mathrm{T}}$ and $a_{\mathrm{C}}$.

\section{Conclusion}

In summary, we presented a new ABA triblock copolymer, PBMA- $b$-PMAA- $b$-PBMA, showing thermally reversible gelation behavior in DMF. The self-assembly process and the relaxation behavior as a function of temperature and concentration were systemically studied using linear rheology, SAXS, and NMR. Our main conclusions are listed as follows: 1) in DMF, the PBMA end blocks self-assemble 
into micelles bridged by the PMAA mid blocks to form a transient network upon cooling below a critical temperature $T_{\mathrm{c}}=5{ }^{\circ} \mathrm{C} ; 2$ ) This $T_{\mathrm{c}}$ determines the intrinsic micellization temperature, which is observed as an inflection temperature in the Arrhenius plot of the shift factor for the time-temperature master curves $\left(\ln a_{\mathrm{T}} \sim 1 / \mathrm{T}\right)$. It provides an effective method to define the micellization point with rheology method for dynamic physical gel with network relaxation time comparable to the experimental observation time; 3) the micelle density and aggregation number per micelle increase with increasing polymer concentration; 4) the activation energy of micelle relaxation, $250 \mathrm{~kJ} / \mathrm{mol}$, is independent of polymer concentration; 5) the network relaxation time scales with polymer concentration following a strong power law relationship $\tau_{\mathrm{L}} \propto C_{\mathrm{P}}^{7.6}$ at a reference temperature of $-20{ }^{\circ} \mathrm{C}$, due to increase in the fraction of bridging chains with polymer concentration; 6) the plateau modulus $G_{\mathrm{N}}$ has a strong dependence on polymer concentration at low concentration regime, and saturates to a relationship $G_{\mathrm{N}} \propto C_{\mathrm{P}}{ }^{1}$ at high concentration due to formation of relative perfect network structure; 7) the fractions of bridge, loop and dangling end blocks are calculated by combing linear rheology, SAXS and NMR at $-20{ }^{\circ} \mathrm{C}$, as $0.40,0.48$, and 0.12 , respectively, for relative perfect network structure; 8) the temperature and concentration are exchangeable in determining $\tau_{\mathrm{L}}$, permitting us to estimate the longest relaxation time at any temperature and concentration, from a given reference longest relaxation time as well as the temperature and concentration shift factors. Since the association of end blocks is caused by the change of solvophobic interactions, the self-assembly process and relaxation mechanism revealed in this work is not specific for cooling-induced association of the PBMA end blocks of 
PBMA- $b$-PMAA- $b$-PBMA polymers, but should be generic for the cooling- or heating-induced association of end blocks of ABA triblock copolymers.

\section{Acknowledgements}

We thank Otsuka Chemical Co., Ltd. for their kind donation of the triblock copolymers. The SAXS experiments were performed at NCPSS BL19U2 beamline at National Center for Protein Sciences Shanghai. We thank the staffs from BL19U2 beamline of National Facility for Protein Science (NFPS) at Shanghai Synchrotron Radiation Facility (SSRF), for assistance during data collection. This research was supported by JSPS KAKENHI (Grant Numbers JP17H06144 and JP19K23617). Institute for Chemical Reaction Design and Discovery (ICReDD) was established by World Premier International Research Initiative (WPI), MEXT, Japan.

\section{Supporting Information}

Schematic of the rheometer geometry; optical images of triblock copolymer and the corresponding homopolymers at high and low temperatures; additional rheology and NMR data; shift factors for TTS and TCS; and method to calculate $d, N_{\mathrm{g}}$ and $\varphi_{\text {sol. }}$.

\section{Reference}

(1) Seitz, M. E.; Burghardt, W. R.; Faber, K. T.; Shull, K. R. Self-Assembly and Stress Relaxation in Acrylic Triblock Copolymer Gels. Macromolecules 2007, 40 (4), $1218-1226$. 
(2) Séréro, Y.; Aznar, R.; Porte, G.; Berret, J. F.; Calvet, D.; Collet, A.; Viguier, M. Associating Polymers: From "Flowers" to Transient Networks. Phys. Rev. Lett. 1998, 81 (25), 5584-5587 DOI: 10.1103/PhysRevLett.81.5584.

(3) Li, L.; Zhang, P.; Zhang, Z.; Lin, Q.; Wu, Y.; Cheng, A.; Lin, Y.; Thompson, C. M.; Smaldone, R. A.; Ke, C. Hierarchical Co-Assembly Enhanced Direct Ink Writing. Angew. Chemie 2018, 130 (18), 5199-5203.

(4) Kim, B.; Park, Y. D.; Min, K.; Lee, J. H.; Hwang, S. S.; Hong, S. M.; Kim, B. H.; Kim, S. O.; Koo, C. M. Electric Actuation of Nanostructured Thermoplastic Elastomer Gels with Ultralarge Electrostriction Coefficients. Adv. Funct. Mater. 2011, 21 (17), 3242-3249.

(5) Shankar, R.; Krishnan, A. K.; Ghosh, T. K.; Spontak, R. J. Triblock Copolymer Organogels as High-Performance Dielectric Elastomers. Macromolecules 2008, 41 (16), 6100-6109.

(6) Kataoka, K.; Harada, A.; Nagasaki, Y. Block Copolymer Micelles for Drug Delivery: Design, Characterization and Biological Significance. Adv. Drug Deliv. Rev. 2012, 64, 37-48.

(7) Madsen, J.; Armes, S. P.; Bertal, K.; Lomas, H.; MacNeil, S.; Lewis, A. L. Biocompatible Wound Dressings Based on Chemically Degradable Triblock Copolymer Hydrogels. Biomacromolecules 2008, 9 (8), 2265-2275.

(8) Ye, Y. N.; Frauenlob, M.; Wang, L.; Tsuda, M.; Sun, T. L.; Cui, K.; Takahashi, R.; Zhang, H. J.; Nakajima, T.; Nonoyama, T. Tough and Self-Recoverable Thin Hydrogel Membranes for Biological Applications. Adv. Funct. Mater. 2018, 
1801489.

(9) Zhang, Z.; Huang, C.; Weiss, R. A.; Chen, Q. Association Energy in Strongly Associative Polymers. J. Rheol. (N. Y. N. Y). 2017, 61 (6), 1199-1207.

(10) Chantawansri, T. L.; Sirk, T. W.; Sliozberg, Y. R. Entangled Triblock Copolymer Gel: Morphological and Mechanical Properties. J. Chem. Phys. 2013, 138 (2), 24908.

(11) Nguyen-Misra, M.; Mattice, W. L. Micellization and Gelation of Symmetric Triblock Copolymers with Insoluble End Blocks. Macromolecules 1995, 28 (5), $1444-1457$.

(12) Ng, W. K.; Tam, K. C.; Jenkins, R. D. Lifetime and Network Relaxation Time of a HEUR-C20 Associative Polymer System. J. Rheol. (N. Y. N. Y). 2000, 44 (1), $137-147$.

(13) Charbonneau, C.; Chassenieux, C.; Colombani, O.; Nicolai, T. Controlling the Dynamics of Self-Assembled Triblock Copolymer Networks via the PH. Macromolecules 2011, 44 (11), 4487-4495.

(14) Henderson, K. J.; Shull, K. R. Effects of Solvent Composition on the Assembly and Relaxation of Triblock Copolymer-Based Polyelectrolyte Gels.

Macromolecules 2012, 45 (3), 1631-1635.

(15) Zabet, M.; Mishra, S.; Boy, R.; Walters, K. B.; Naskar, A. K.; Kundu, S. Temperature-Dependent Self-Assembly and Rheological Behavior of a Thermoreversible Pmma-PnBA-PMMA Triblock Copolymer Gel. J. Polym. Sci. Part B Polym. Phys. 2017, 55 (11), 877-887. 
(16) Angelopoulos, S. A.; Tsitsilianis, C. Thermo-Reversible Hydrogels Based on Poly(N,N-Diethylacrylamide)-Block- Poly(Acrylic Acid)-Block-Poly(N,N-Diethylacrylamide) Double Hydrophilic Triblock Copolymer. Macromol. Chem. Phys. 2006, 207 (23), 2188-2194.

(17) Stavrouli, N.; Aubry, T.; Tsitsilianis, C. Rheological Properties of ABA Telechelic Polyelectrolyte and ABA Polyampholyte Reversible Hydrogels: A Comparative Study. Polymer (Guildf). 2008, 49 (5), 1249-1256.

(18) Tsitsilianis, C.; Iliopoulos, I. Viscoelastic Properties of Physical Gels Formed by Associative Telechelic Polyelectrolytes in Aqueous Media. Macromolecules 2002, $35(9), 3662-3667$.

(19) Inomata, K.; Nakanishi, D.; Banno, A.; Nakanishi, E.; Abe, Y.; Kurihara, R.; Fujimoto, K.; Nose, T. Association and Physical Gelation of ABA Triblock Copolymer in Selective Solvent. Polymer (Guildf). 2003, 44 (18), 5303-5310.

(20) Halperin, A.; Alexander, S. Polymeric Micelles: Their Relaxation Kinetics. Macromolecules 1989, 22 (5), 2403-2412.

(21) Castelletto, V.; Hamley, I. W.; Yuan, X. F.; Kelarakis, A.; Booth, C. Structure and Rheology of Aqueous Micellar Solutions and Gels Formed from an Associative Poly(Oxybutylene)-Poly(Oxyethylene)-Poly(Oxybutylene) Triblock Copolymer. Soft Matter 2005, 1 (2), 138-145.

(22) Tsitsilianis, C.; Serras, G.; Ko, C.-H.; Jung, F.; Papadakis, C. M.; Rikkou-Kalourkoti, M.; Patrickios, C. S.; Schweins, R.; Chassenieux, C. Thermoresponsive Hydrogels Based on Telechelic Polyelectrolytes: From 
Dynamic to "Frozen” Networks. Macromolecules 2018, 51 (6), 2169-2179.

(23) Winter, H. H.; Chambon, F. Analysis of Linear Viscoelasticity of a Crosslinking Polymer at the Gel Point. J. Rheol. (N. Y. N. Y). 1986, 30 (2), 367-382.

(24) Chiou, B.-S.; Raghavan, S. R.; Khan, S. A. Effect of Colloidal Fillers on the Cross-Linking of a UV-Curable Polymer: Gel Point Rheology and the WinterChambon Criterion. Macromolecules 2001, 34 (13), 4526-4533.

(25) S., D. M. . N. K. . R.-M. The Sol-Gel Transition. In Physical Gels from Biological and Synthetic Polymers; Cambridge University Press: Cambridge, 2013.

(26) Wakimoto, K.; Sasaki, H.; Arai, N. Dissipative Particle Dynamics Simulation of the Relaxation Behaviour of a Triblock Copolymer Supramolecular Network. Mol. Simul. 2018, 44 (7), 534-539.

(27) Urzhumtsev, Y. S. Time-Temperature Superposition. Review. Polym. Mech. 1975, $11(1), 57-72$.

(28) Rubinstein, M.; Colby, R. H. Polymer Physics; Oxford university press New York, 2003.

(29) Vega, D. A.; Sebastian, J. M.; Loo, Y.; Register, R. A. Phase Behavior and Viscoelastic Properties of Entangled Block Copolymer Gels. J. Polym. Sci. Part B Polym. Phys. 2001, 39 (18), 2183-2197.

(30) Mischenko, N.; Reynders, K.; Koch, M. H. J.; Mortensen, K.; Pedersen, J. S.;

Fontaine, F.; Graulus, R.; Reynaers, H. Small-Angle x-Ray and Neutron Scattering from Bulk and Oriented Triblock Copolymer Gels. Macromolecules 1995, 28 (6), 2054-2062. 
(31) Kinning, D. J.; Thomas, E. L. Hard-Sphere Interactions between Spherical Domains in Diblock Copolymers. Macromolecules 1984, 17 (9), 1712-1718.

(32) Flanigan, C. M.; Crosby, A. J.; Shull, K. R. Structural Development and Adhesion of Acrylic ABA Triblock Copolymer Gels. Macromolecules 1999, 32 (21), $7251-7262$.

(33) Bansil, R.; Nie, H.; Li, Y.; Liao, G.; Ludwig, K.; Steinhart, M.; Koňák, Č.; Lal, J. Structure and Ordering Kinetics of Micelles in Triblock Copolymer Solutions in Selective Solvents. In Macromolecular Symposia; Wiley Online Library, 2002; Vol. 190, pp 161-172.

(34) Gottlieb, H. E.; Kotlyar, V.; Nudelman, A. NMR Chemical Shifts of Common Laboratory Solvents as Trace Impurities. J. Org. Chem. 1997, 62 (21), 7512-7515.

(35) Guo, H.; Brûlet, A.; Rajamohanan, P. R.; Marcellan, A.; Sanson, N.; Hourdet, D. Influence of Topology of LCST-Based Graft Copolymers on Responsive Assembling in Aqueous Media. Polymer (Guildf). 2015, 60, 164-175 DOI: 10.1016/j.polymer.2015.01.038.

(36) Hoffman, R. E. Standardization of Chemical Shifts of TMS and Solvent Signals in NMR Solvents. Magn. Reson. Chem. 2006, 44 (6), 606-616.

(37) Drzal, P. L.; Shull, K. R. Origins of Mechanical Strength and Elasticity in Thermally Reversible, Acrylic Triblock Copolymer Gels. Macromolecules 2003, 36 (6), 2000-2008.

(38) Khatory, A.; Lequeux, F.; Kern, F.; Candau, S. J. Linear and Nonlinear Viscoelasticity of Semidilute Solutions of Wormlike Micelles at High Salt Content. 
Langmuir 1993, 9 (6), 1456-1464.

(39) Cates, M. E. Reptation of Living Polymers: Dynamics of Entangled Polymers in the Presence of Reversible Chain-Scission Reactions. Macromolecules 1987, 20 (9), 2289-2296.

(40) Rubinstein, M.; Semenov, A. N. Dynamics of Entangled Solutions of Associating Polymers. Macromolecules 2001, 34 (4), 1058-1068.

(41) Tanaka, F.; Edwards, S. F. Viscoelastic Properties of Physically Crosslinked Networks. 1. Transient Network Theory. Macromolecules 1992, 25 (5), $1516-1523$.

(42) Polymer database http://polymerdatabase.com/polymers/polymethacrylicacid.html (accessed Dec 3, 2015).

(43) Liu, C.; He, J.; Van Ruymbeke, E.; Keunings, R.; Bailly, C. Evaluation of Different Methods for the Determination of the Plateau Modulus and the Entanglement Molecular Weight. Polymer (Guildf). 2006, 47 (13), 4461-4479.

(44) Seitz, M. E.; Burghardt, W. R.; Shull, K. R. Micelle Morphology and Mechanical Response of Triblock Gels. Macromolecules 2009, 42 (22), 9133-9140. 
Relaxation Dynamics and Underlying Mechanism of a Thermally Reversible Gel from Symmetric Triblock Copolymer

Ya Nan Ye ${ }^{1}$, Kunpeng Cui ${ }^{2}$, Tsutomu Indei ${ }^{3}$, Tasuku Nakajima ${ }^{1,2,3}$, Dominique Hourdet ${ }^{3,4}$, Takayuki Kurokawa ${ }^{1,3}$ and Jian Ping Gong ${ }^{1,2,3 *}$

for Table of Contents use only

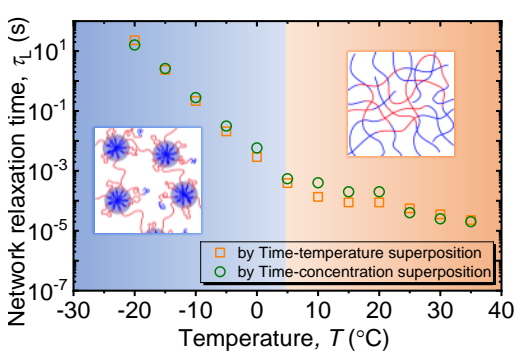




\section{Relaxation Dynamics and Underlying Mechanism of a Thermally Reversible Gel}

\section{from Symmetric Triblock Copolymer}

Ya Nan Ye ${ }^{1}$, Kunpeng Cui ${ }^{2 *}$, Tsutomu Indei ${ }^{3}$, Tasuku Nakajima ${ }^{1,2,3}$, Dominique Hourdet $^{3,4}$, Takayuki Kurokawa ${ }^{1,3}$, and Jian Ping Gong ${ }^{1,2,3 *}$

${ }^{1}$ Faculty of Advanced Life Science, Hokkaido University, Sapporo 001-0021, Japan, ${ }^{2}$ Institute for Chemical Reaction Design and Discovery (WPI-ICReDD), Hokkaido University, Sapporo 001-0021, Japan,

${ }^{3}$ Global Institution for Collaborative Research and Education (GI-CoRE), Hokkaido University, Sapporo 001-0021, Japan.

${ }^{4}$ Laboratoire Sciences et Ingénierie de la Matière Molle, ESPCI Paris, PSL University, Sorbonne Université, CNRS, Paris, F-75005, France.

*: Corresponding author, Email: kpcui@sci.hokudai.ac.jp, gong@sci.hokudai.ac.jp

Table S1. The monomer concentrations $C_{P}$ of triblock copolymer/DMF samples and the corresponding polymer weight fractions $\mathrm{W}_{\mathrm{P}}$.

\begin{tabular}{lllllllll}
\hline $\mathrm{C}_{\mathrm{P}}(\mathrm{mol} / \mathrm{L})$ & 0.91 & 1.14 & 1.26 & 1.38 & 1.50 & 1.98 & 2.09 & 2.21 \\
$\mathrm{~W}_{\mathrm{P}}(\mathrm{wt} \%)$ & 11.5 & 14.5 & 16.0 & 17.5 & 19.0 & 25.0 & 26.5 & 28.0 \\
\hline
\end{tabular}

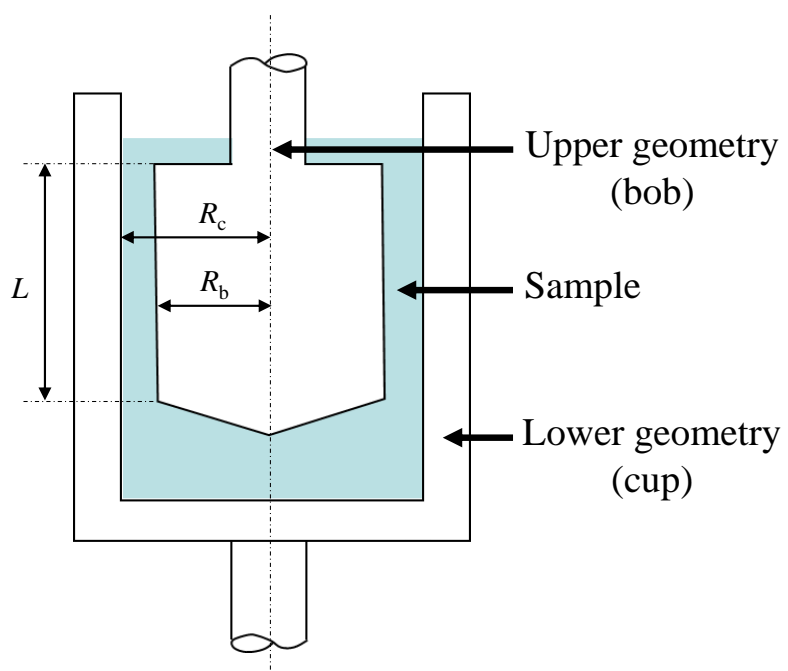

Figure S1. A schematic of the concentric cylinder geometry, where $R_{\mathrm{b}}$ is bob radius, $R_{\mathrm{c}}$ is cup radius and $L$ is the bob length. 

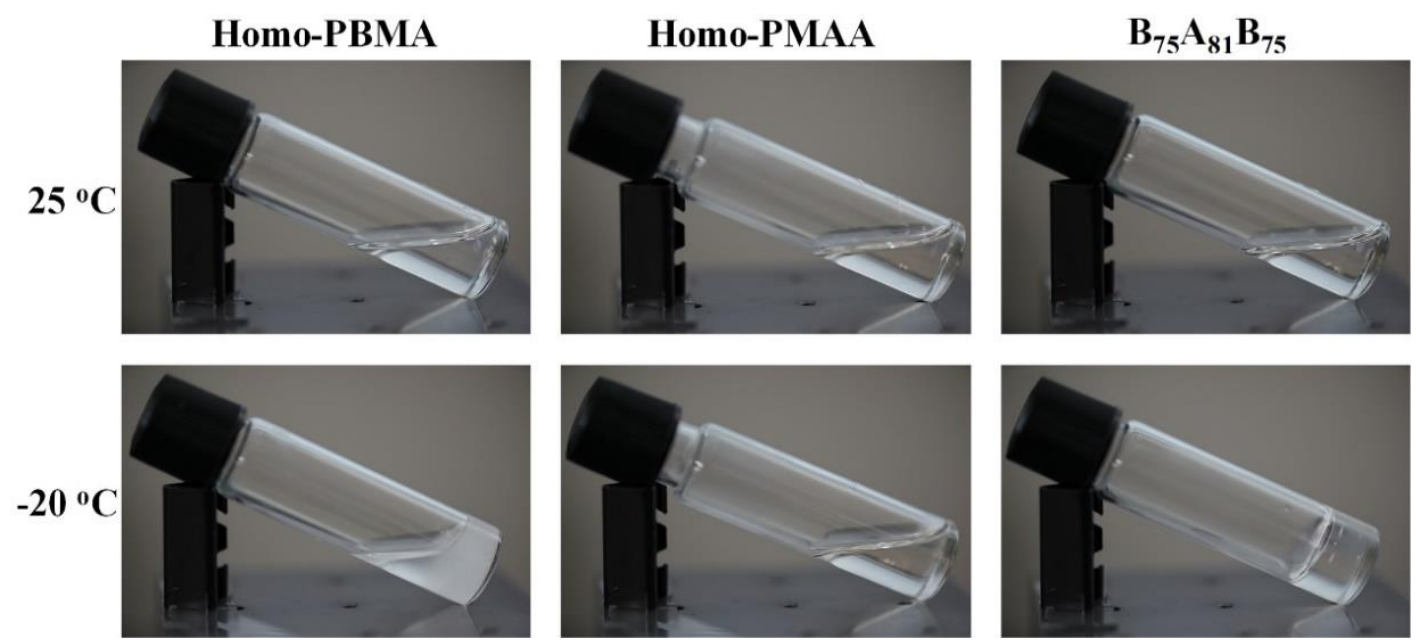

Figure S2. Optical images of homopolymers PBMA and PMAA, and triblock copolymer in DMF at $25^{\circ} \mathrm{C}$ and $-20^{\circ} \mathrm{C}$, respectively $\left(C_{\mathrm{P}}: 1.98 \mathrm{~mol} / \mathrm{L}\right)$.

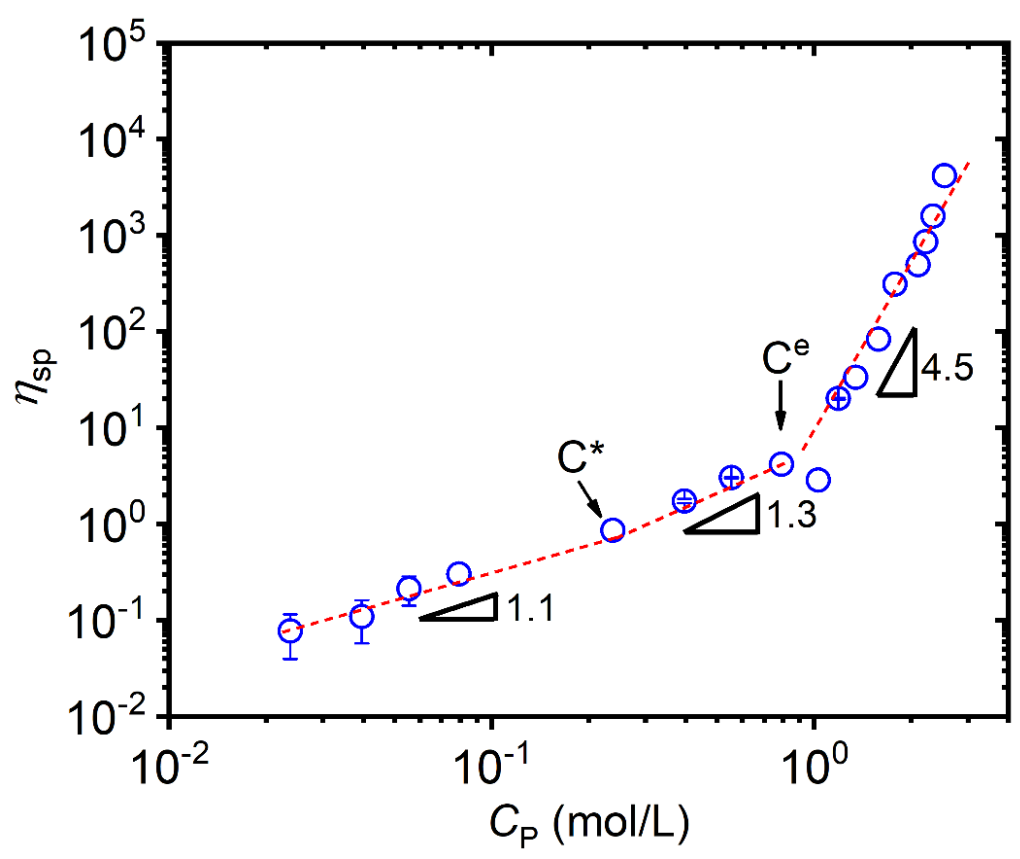

Figure S3. Scaling relationship between specific viscosity $\eta_{\mathrm{sp}}=\left(\eta-\eta_{\mathrm{s}}\right) / \eta_{\mathrm{s}}$ and concentration $C_{\mathrm{P}}$ for triblock copolymer DMF solution at $25^{\circ} \mathrm{C}$. Here $\eta$ and $\eta_{\mathrm{s}}$ are the zero-shear viscosity of triblock copolymer solution and pure DMF solvent at $25{ }^{\circ} \mathrm{C}$, respectively. The overlap concentration $\left(\mathrm{C}^{*}=\right.$ $0.21 \mathrm{~mol} / \mathrm{L})$ and the entanglement concentration $\left(\mathrm{C}^{\mathrm{e}}=0.79 \mathrm{~mol} / \mathrm{L}\right)$ at $25^{\circ} \mathrm{C}$ can be obtained from scaling relationship ${ }^{1}$. 


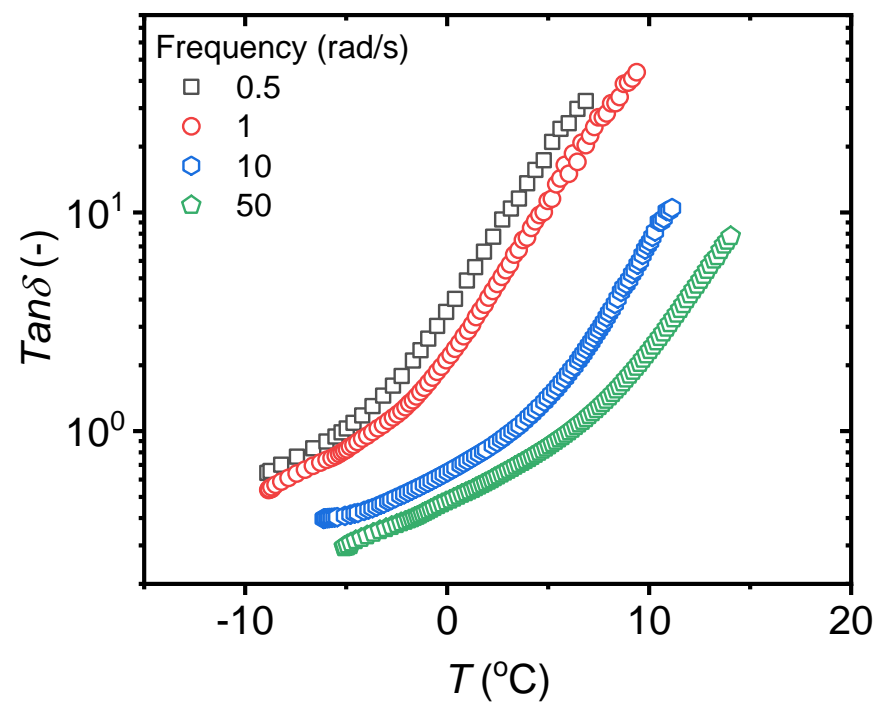

Figure S4. Temperature dependence of loss factor $\tan \delta$ at $\omega=0.5,1,10$ and $50 \mathrm{rad} / \mathrm{s}$ for triblock copolymer/DMF with a concentration $\left(C_{\mathrm{P}}\right)$ of $1.98 \mathrm{~mol} / \mathrm{L}$.

(a)

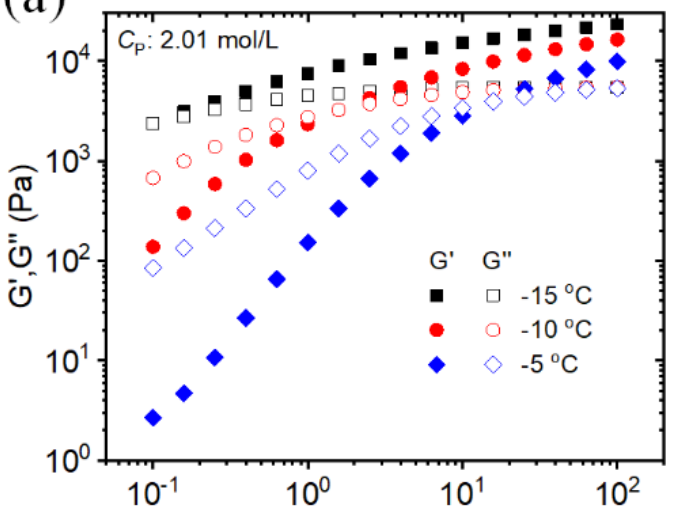

(c)

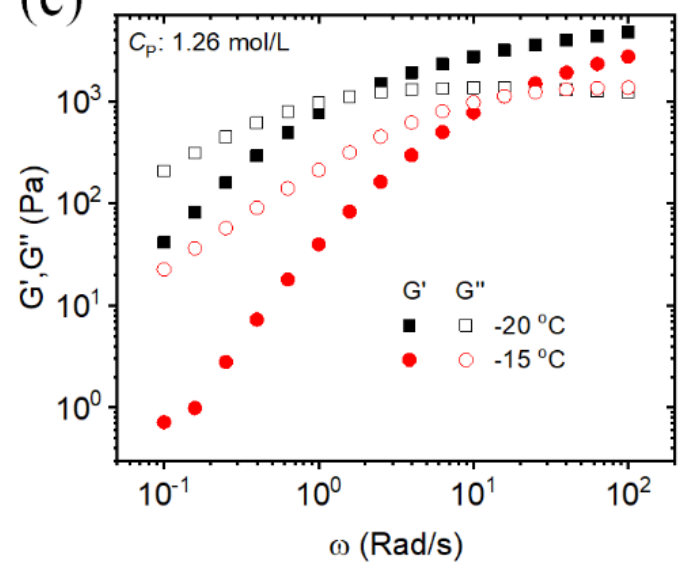

(b)

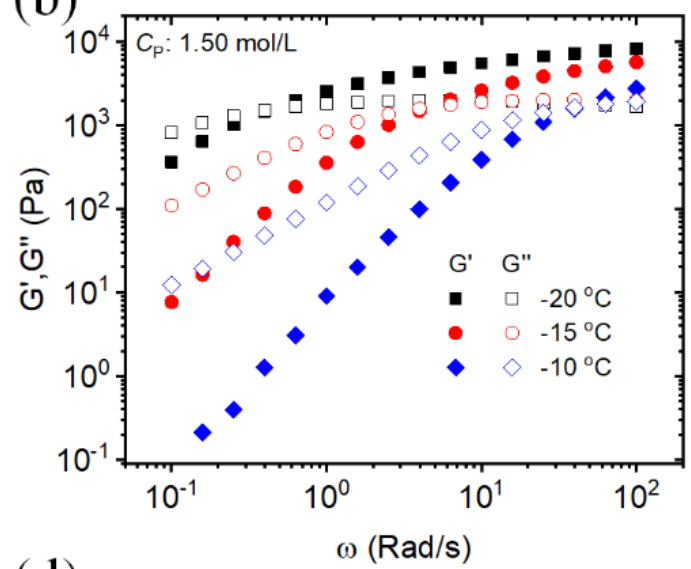

(d)

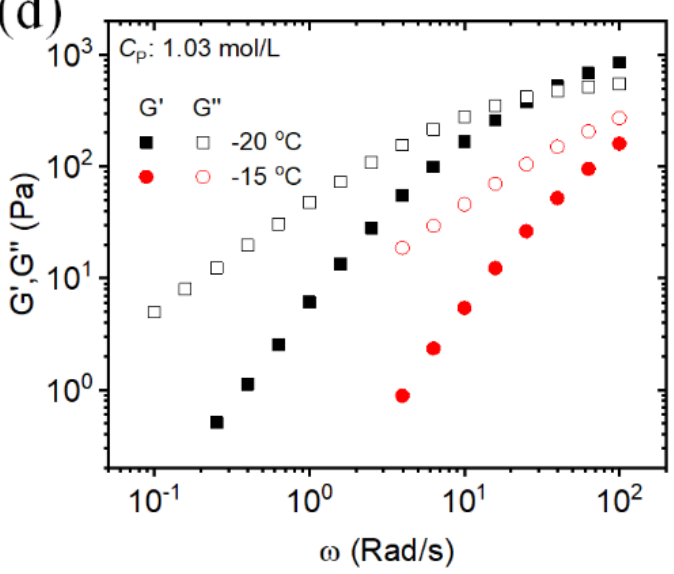

Figure S5. Frequency dependence of storage moduli $G^{\prime}$ (filled) and loss moduli $G^{\prime \prime}$ (unfilled) for triblock copolymer/DMF at different temperatures with concentrations of (a) $2.01 \mathrm{~mol} / \mathrm{L}$, (b) 1.50 $\mathrm{mol} / \mathrm{L}$, (c) $1.26 \mathrm{~mol} / \mathrm{L}$ and (d) $1.03 \mathrm{~mol} / \mathrm{L}$. 
(a)
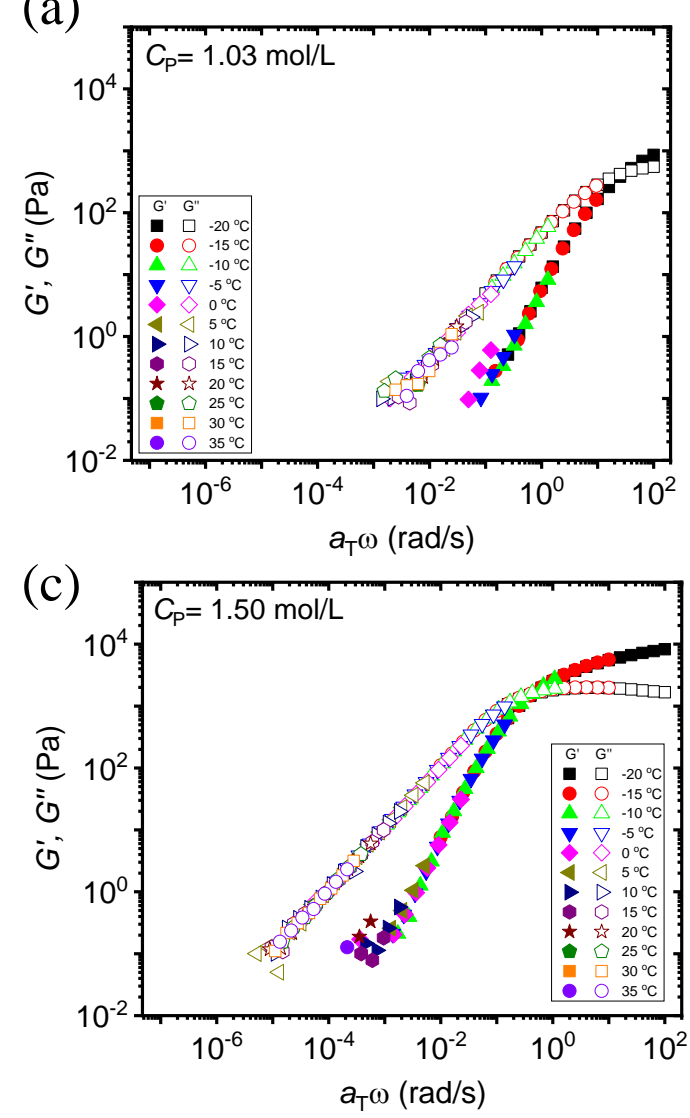

(b)
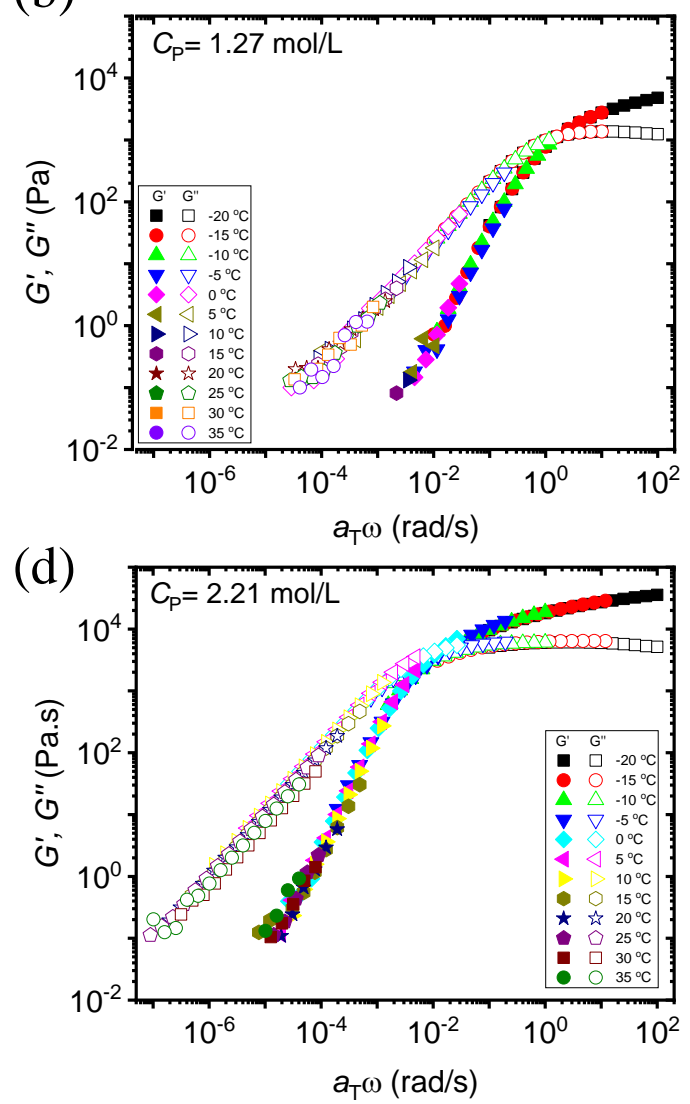

Figure S6. Representative time-temperature superposition master curves illustrating storage modulus $G^{\prime}$ and loss modulus $G^{\prime \prime}$ for triblock copolymer/DMF with concentrations of (a) $C_{\mathrm{p}}=1.03$ $\mathrm{mol} / \mathrm{L}$, (b) $C_{\mathrm{p}}=1.27 \mathrm{~mol} / \mathrm{L}$, (c) $C_{\mathrm{p}}=1.50 \mathrm{~mol} / \mathrm{L}$ and (d) $C_{\mathrm{p}}=2.21 \mathrm{~mol} / \mathrm{L}$. Reference temperature is $-20{ }^{\circ} \mathrm{C}$.

(a)

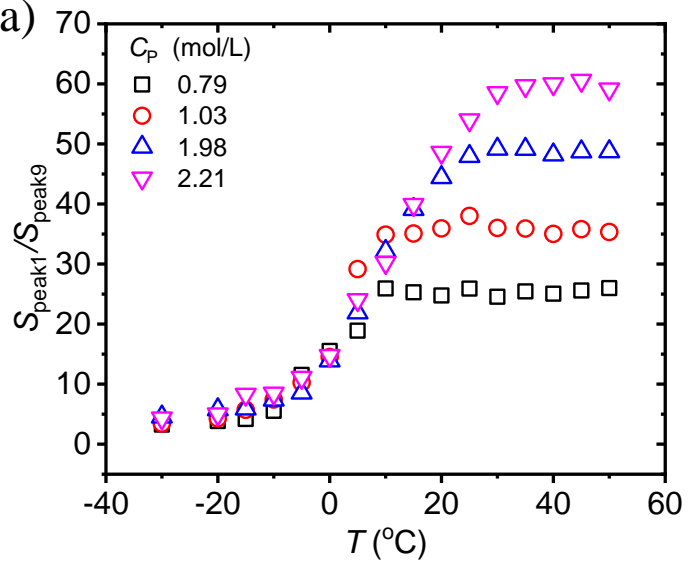

(b)

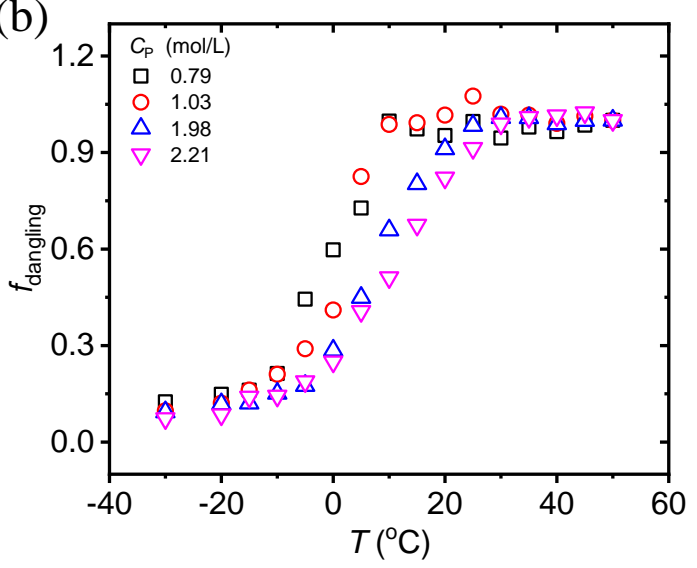

Figure S7. (a) Temperature dependence of normalized NMR area ratio of peak1 to peak $9, S_{n}$ $(\mathrm{T})=\mathrm{S}_{\text {peak } 1} / \mathrm{S}_{\text {peak }}$, and (b) fraction of dangling chains, $f_{\text {dangling, at different temperatures for various }}$ polymer concentrations. $f_{\text {dangling }}$ is calculated by dividing the normalized area ratio $S_{n}(T)$ with that at the plateau regime at high temperatures, $\mathrm{S}_{\mathrm{n} \text {, plateau. }}$ 
(a)

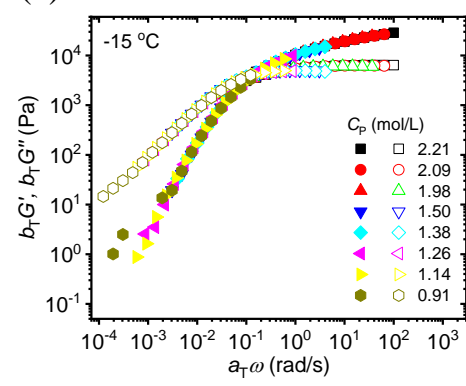

(d)

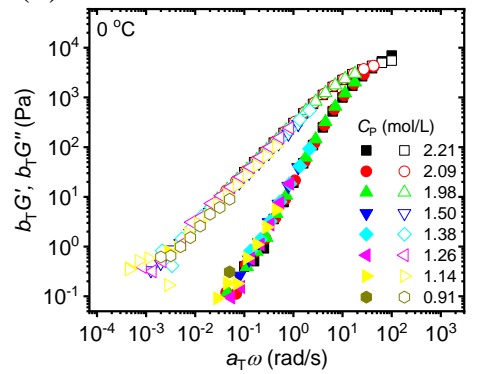

(b)

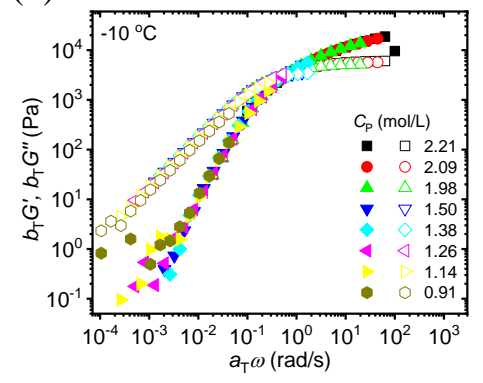

(e)

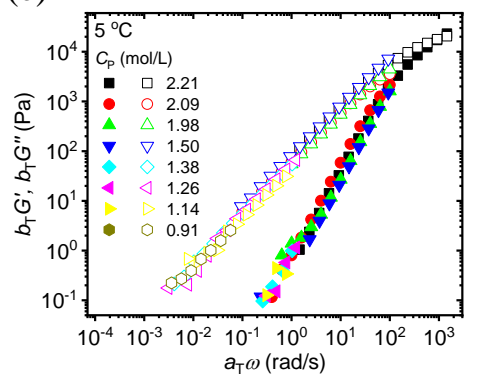

(c)

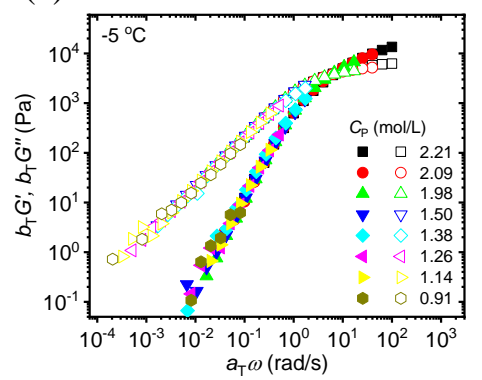

Figure S8. Representative time-concentration superposition master curves illustrating storage modulus $G^{\prime}$ and loss modulus $G^{\prime \prime}$ for triblock copolymer solution at temperatures of (a) $-15^{\circ} \mathrm{C}$, (b) $-10{ }^{\circ} \mathrm{C}$, (c) $-5^{\circ} \mathrm{C},(\mathrm{d}) 0^{\circ} \mathrm{C}$ and (e) $5^{\circ} \mathrm{C}$ (Reference concentration $\left(C_{\mathrm{P}}\right)$ is $2.21 \mathrm{~mol} / \mathrm{L}$ ).

(a)
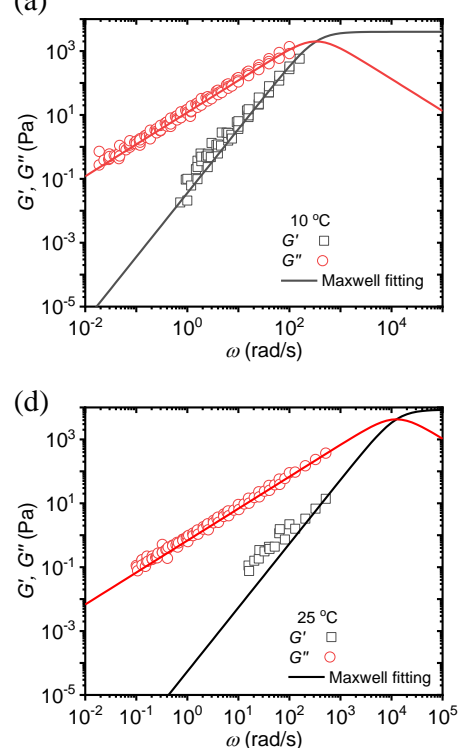

(b)
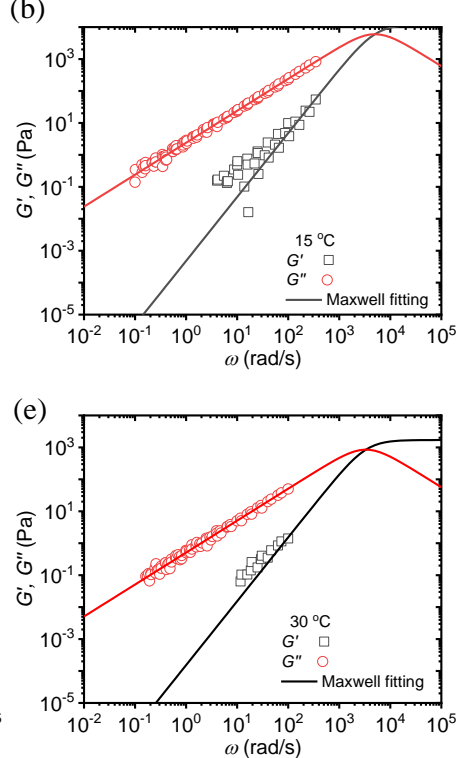

(c)
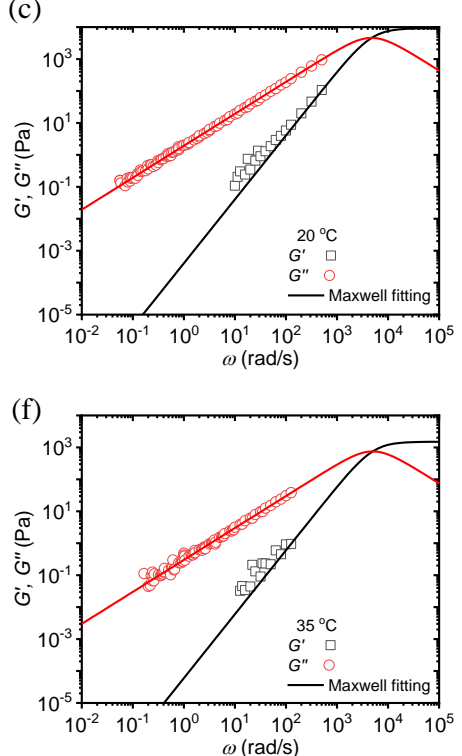

Figure S9. Fitting of storage modulus $G^{\prime}$ and loss modulus $G^{\prime \prime}$ with Maxwell model for triblock copolymer solution at temperatures of (a) $10{ }^{\circ} \mathrm{C}$, (b) $15{ }^{\circ} \mathrm{C}$, (c) $20{ }^{\circ} \mathrm{C}$, (d) $25{ }^{\circ} \mathrm{C}$, (e) $30{ }^{\circ} \mathrm{C}$ and (f) $35{ }^{\circ} \mathrm{C}$ (Reference concentration $\left(C_{\mathrm{P}}\right)$ is $\left.2.21 \mathrm{~mol} / \mathrm{L}\right)$. 
Table S2. The parallel shift factor $a_{\mathrm{T}}$ obtained by TTS at the reference temperature of $-20{ }^{\circ} \mathrm{C}$.

\begin{tabular}{|c|c|c|c|c|c|c|c|c|}
\hline \multirow{2}{*}{$\begin{array}{c}T \\
\left({ }^{\circ} \mathrm{C}\right)\end{array}$} & \multicolumn{8}{|c|}{$C_{\mathrm{P}}(\mathrm{mol} / \mathrm{L})$} \\
\hline & 0.91 & 1.14 & 1.26 & 1.38 & 1.50 & 1.98 & 2.09 & 2.21 \\
\hline-20 & 1 & 1 & 1 & 1 & 1 & 1 & 1 & 1 \\
\hline-15 & $1.0 \times 10^{-1}$ & $9.9 \times 10^{-2}$ & $1.0 \times 10^{-1}$ & $1.0 \times 10^{-1}$ & $1.0 \times 10^{-1}$ & $1.3 \times 10^{-1}$ & $1.1 \times 10^{-1}$ & $1.2 \times 10^{-1}$ \\
\hline-10 & $1.3 \times 10^{-2}$ & $1.1 \times 10^{-2}$ & $1.2 \times 10^{-2}$ & $1.2 \times 10^{-2}$ & $1.1 \times 10^{-2}$ & $1.5 \times 10^{-2}$ & $1.7 \times 10^{-2}$ & $1.6 \times 10^{-2}$ \\
\hline-5 & $2.4 \times 10^{-3}$ & $1.5 \times 10^{-3}$ & $1.5 \times 10^{-3}$ & $1.4 \times 10^{-3}$ & $1.4 \times 10^{-3}$ & $1.7 \times 10^{-3}$ & $2.0 \times 10^{-3}$ & $2.1 \times 10^{-3}$ \\
\hline 0 & $7.9 \times 10^{-4}$ & $2.9 \times 10^{-4}$ & $2.9 \times 10^{-4}$ & $2.2 \times 10^{-4}$ & $2.3 \times 10^{-4}$ & $2.6 \times 10^{-4}$ & $2.9 \times 10^{-4}$ & $2.9 \times 10^{-4}$ \\
\hline 5 & $4.1 \times 10^{-4}$ & $9.8 \times 10^{-5}$ & $8.6 \times 10^{-5}$ & $4.3 \times 10^{-5}$ & $5.2 \times 10^{-5}$ & $5.3 \times 10^{-5}$ & $5.9 \times 10^{-5}$ & $5.6 \times 10^{-5}$ \\
\hline 10 & $2.6 \times 10^{-4}$ & $4.6 \times 10^{-5}$ & $3.6 \times 10^{-5}$ & $1.4 \times 10^{-5}$ & $1.8 \times 10^{-5}$ & $1.5 \times 10^{-5}$ & $1.6 \times 10^{-5}$ & $1.2 \times 10^{-5}$ \\
\hline 15 & $2.1 \times 10^{-4}$ & $2.9 \times 10^{-5}$ & $1.8 \times 10^{-5}$ & $5.4 \times 10^{-6}$ & $9.5 \times 10^{-6}$ & $5.5 \times 10^{-6}$ & $5.1 \times 10^{-6}$ & $3.9 \times 10^{-6}$ \\
\hline 20 & $1.7 \times 10^{-4}$ & $2.3 \times 10^{-5}$ & $1.1 \times 10^{-5}$ & $3.7 \times 10^{-6}$ & $5.6 \times 10^{-6}$ & $2.6 \times 10^{-6}$ & $2.3 \times 10^{-6}$ & $1.9 \times 10^{-6}$ \\
\hline 25 & $1.5 \times 10^{-4}$ & $1.8 \times 10^{-5}$ & $9.2 \times 10^{-6}$ & $2.4 \times 10^{-6}$ & $3.8 \times 10^{-6}$ & $1.3 \times 10^{-6}$ & $1.3 \times 10^{-6}$ & $9.0 \times 10^{-7}$ \\
\hline 30 & $1.2 \times 10^{-4}$ & $1.3 \times 10^{-5}$ & $7.4 \times 10^{-6}$ & $1.8 \times 10^{-6}$ & $2.8 \times 10^{-6}$ & $7.8 \times 10^{-7}$ & $6.7 \times 10^{-7}$ & $4.1 \times 10^{-7}$ \\
\hline 35 & $1.4 \times 10^{-4}$ & $1.3 \times 10^{-5}$ & $5.8 \times 10^{-6}$ & $1.3 \times 10^{-6}$ & $2.1 \times 10^{-6}$ & $5.9 \times 10^{-7}$ & $4.2 \times 10^{-7}$ & $2.6 \times 10^{-7}$ \\
\hline
\end{tabular}


Table S3. The parallel shift factor $a_{\mathrm{C}}$ obtained by TCS at the reference concentration of 1.98 $\mathrm{mol} / \mathrm{L}$.

\begin{tabular}{|c|c|c|c|c|c|c|c|c|}
\hline \multirow{2}{*}{$\begin{array}{c}T \\
\left({ }^{\circ} \mathrm{C}\right)\end{array}$} & \multicolumn{8}{|c|}{$C_{\mathrm{P}}(\mathrm{mol} / \mathrm{L})$} \\
\hline & 0.91 & 1.14 & 1.26 & 1.38 & 1.50 & 1.98 & 2.09 & 2.21 \\
\hline-20 & $2.5 \times 10^{-3}$ & $1.5 \times 10^{-2}$ & $2.3 \times 10^{-2}$ & $1.2 \times 10^{-1}$ & $8.3 \times 10^{-1}$ & $4.9 \times 10^{-1}$ & $7.4 \times 10^{-1}$ & 1 \\
\hline-15 & $1.2 \times 10^{-3}$ & $5.8 \times 10^{-3}$ & $8.6 \times 10^{-3}$ & $4.0 \times 10^{-2}$ & $3.1 \times 10^{-2}$ & $3.6 \times 10^{-1}$ & $6.4 \times 10^{-1}$ & 1 \\
\hline-10 & $4.2 \times 10^{-4}$ & $2.6 \times 10^{-3}$ & $5.1 \times 10^{-3}$ & $1.7 \times 10^{-2}$ & $1.3 \times 10^{-2}$ & $2.0 \times 10^{-1}$ & $4.5 \times 10^{-1}$ & 1 \\
\hline-5 & $8.2 \times 10^{-4}$ & $3.3 \times 10^{-3}$ & $5.2 \times 10^{-3}$ & $1.7 \times 10^{-2}$ & $1.7 \times 10^{-2}$ & $1.7 \times 10^{-1}$ & $4.0 \times 10^{-1}$ & 1 \\
\hline 0 & $5.0 \times 10^{-4}$ & $4.5 \times 10^{-3}$ & $8.5 \times 10^{-3}$ & $2.1 \times 10^{-2}$ & $1.2 \times 10^{-2}$ & $1.8 \times 10^{-1}$ & $4.3 \times 10^{-1}$ & 1 \\
\hline 5 & $7.8 \times 10^{-4}$ & $5.7 \times 10^{-3}$ & $7.8 \times 10^{-3}$ & $1.2 \times 10^{-2}$ & $1.0 \times 10^{-2}$ & $9.3 \times 10^{-1}$ & $9.9 \times 10^{-1}$ & 1 \\
\hline 10 & - & - & $2.4 \times 10^{-2}$ & $7.5 \times 10^{-2}$ & $7.2 \times 10^{-2}$ & $1.8 \times 10^{-1}$ & $3.6 \times 10^{-1}$ & 1 \\
\hline 15 & - & - & - & $6.0 \times 10^{-3}$ & $4.5 \times 10^{-2}$ & $4.0 \times 10^{-1}$ & $8.7 \times 10^{-1}$ & 1 \\
\hline 20 & - & - & - & $7.8 \times 10^{-3}$ & $9.2 \times 10^{-3}$ & $3.1 \times 10^{-2}$ & $2.8 \times 10^{-1}$ & 1 \\
\hline 25 & - & - & - & - & $1.3 \times 10^{-2}$ & $6.0 \times 10^{-2}$ & $6.4 \times 10^{-1}$ & 1 \\
\hline 30 & - & - & - & - & $1.0 \times 10^{-2}$ & $3.9 \times 10^{-2}$ & $3.2 \times 10^{-1}$ & 1 \\
\hline 35 & - & - & - & - & - & $4.1 \times 10^{-2}$ & $9.4 \times 10^{-2}$ & 1 \\
\hline
\end{tabular}

*: The '-' represents the shift factor $a_{\mathrm{C}}$ which cannot be obtained by TCS due to the data accuracy limited by rheology resolution.

\section{Calculation of $d, N_{\mathrm{g}}$ and $\varphi_{\mathrm{sol}}$}

The 1D SAXS profile of triblock copolymer/DMF at $-20{ }^{\circ} \mathrm{C}$ was fitted by the core-shell model with hard sphere repulsions ${ }^{2-5}$. This model describes interacting hard cores surrounded by outer shell. According to this model, the scattering intensity can be expressed as

$$
I(q)=K N S(q) P(q)
$$

Here $K$ is a constant, $N$ is the number of scatters, $S(q)$ is the structure factor accounting for the inter-particle correlation, and $P(q)$ is the form factor accounting for the shape of particle. The 1D SAXS profile was fitted with SasView software with 
four parameters $r,(\Delta r) / r, t$ and $\eta$, where $r$ represents the radius of the hard core, $(\Delta r) / r$ represents the standard deviation over the mean value $r, t$ represents the shell thickness, and $\eta$ represents the volume fraction of hard-core and shell parts. Based on above fitting parameters the average distance between micelles, $d$, is given by ${ }^{6}$

$$
d=\frac{2 \pi}{q}
$$

The aggregation number, $N_{\mathrm{g}}$, or the number of end blocks per micelle, is given by

$$
N_{g}=\left(1-f_{\text {dangling }}\right)\left(\frac{2 C_{P} N_{a}}{N}\right) \times d^{3}
$$

where $N_{a}$ is Avogadro's number, and $N$ is the degree of polymerization of the triblock copolymer.

The volume occupied by end blocks themselves per micelle can be calculated by the following equation:

$$
V_{\text {endblock }}=\frac{M_{\text {endblock }}}{\rho_{\text {endblock }} N_{A}} N_{g}
$$

where $M_{\text {endblock }}$ and $\rho_{\text {endblock }}$ is the number average molecular weight of one end block and the corresponding bulk polymer density of the end block without solvent, respectively. $M_{\text {endblock }}=10650 \mathrm{~g} / \mathrm{mol}$ and $\rho_{\text {endblock }}=1180 \mathrm{~kg} / \mathrm{m}^{3}$ were used for the PBMA end block. For $C_{\mathrm{P}}=1.98 \mathrm{~mol} / \mathrm{L}$ at $-20{ }^{\circ} \mathrm{C}$, the $N_{\mathrm{g}}$ is 252 . It gives a PBMA volume of $3752.5 \mathrm{~nm}^{3}$.

The volume occupied by a micelle is:

$$
V_{\text {micelle }}=\frac{4}{3} \pi(r+t)^{3}
$$

The solvent volume fraction in a micelle, $\varphi_{\text {sol }}$, is given by ${ }^{7}$

$$
\varphi_{\text {sol }}=1-\frac{V_{\text {endblock }}}{V_{\text {micelle }}}=1-\frac{3 N_{g} M_{\text {endblock }}}{4 \pi(r+t)^{3} N_{a} \rho_{\text {endblock }}}
$$




\section{Reference}

(1) Rubinstein, M.; Colby, R. H. Polymer Physics; Oxford university press New York, 2003.

(2) Mischenko, N.; Reynders, K.; Koch, M. H. J.; Mortensen, K.; Pedersen, J. S.; Fontaine, F.; Graulus, R.; Reynaers, H. Small-Angle x-Ray and Neutron Scattering from Bulk and Oriented Triblock Copolymer Gels. Macromolecules 1995, 28 (6), 2054-2062.

(3) Kinning, D. J.; Thomas, E. L. Hard-Sphere Interactions between Spherical Domains in Diblock Copolymers. Macromolecules 1984, 17 (9), 1712-1718.

(4) Flanigan, C. M.; Crosby, A. J.; Shull, K. R. Structural Development and Adhesion of Acrylic ABA Triblock Copolymer Gels. Macromolecules 1999, $32(21), 7251-7262$.

(5) Bansil, R.; Nie, H.; Li, Y.; Liao, G.; Ludwig, K.; Steinhart, M.; Koňák, Č.; Lal, J. Structure and Ordering Kinetics of Micelles in Triblock Copolymer Solutions in Selective Solvents. In Macromolecular Symposia; Wiley Online Library, 2002; Vol. 190, pp 161-172.

(6) Seitz, M. E.; Burghardt, W. R.; Faber, K. T.; Shull, K. R. Self-Assembly and Stress Relaxation in Acrylic Triblock Copolymer Gels. Macromolecules 2007, $40(4), 1218-1226$.

(7) Nguyen-Misra, M.; Mattice, W. L. Micellization and Gelation of Symmetric Triblock Copolymers with Insoluble End Blocks. Macromolecules 1995, 28 (5), $1444-1457$. 